Research Article

\title{
The Analysis of Time-Space Effect of Surrounding Rock Deformation of TBM Tunnels in Deep Composite Stratum with or without Support
}

\author{
Xiaoming Sun $\mathbb{D}^{\mathrm{D}},{ }^{1}$ Chao Ren, ${ }^{1}$ Junchao Yuan, ${ }^{1}$ Jianming Du, ${ }^{2}$ Jinshan Liu, ${ }^{3}$ and Bo Guo ${ }^{1}$ \\ ${ }^{1}$ State Key Laboratory for Geomechanics \& Deep Underground Engineering, School of Mechanics and Civil Engineering, \\ China University of Mining \& Technology (Beijing), Beijing 100083, China \\ ${ }^{2}$ Key Laboratory for Urban Underground Engineering of the Education Ministry, Beijing 100044, China \\ ${ }^{3}$ State Key Laboratory for Geomechanics \& Deep Underground Engineering, School of Mechanics and Civil Engineering, \\ China University of Mining \& Technology, Xuzhou 221116, China \\ Correspondence should be addressed to Xiaoming Sun; 108830@cumtb.edu.cn
}

Received 28 January 2020; Revised 18 May 2020; Accepted 19 June 2020; Published 7 July 2020

Academic Editor: Peixin Shi

Copyright ( 92020 Xiaoming Sun et al. This is an open access article distributed under the Creative Commons Attribution License, which permits unrestricted use, distribution, and reproduction in any medium, provided the original work is properly cited.

In view of difficult problems such as excavation, segment simulation, deformation, and force measurement in the small-scale model testing of deep composite stratum TBM tunnel, the TBM simulation experimental device, the model segment ring prefabrication device, and the digital photogrammetry technology were comprehensively adopted. Also, the calculation methods were proposed. The analysis of the deformation characteristics as well as rupture of surrounding rock revealed those space-time effects: (1) When no support existed, the space-time effect of the surrounding rock deformation was concentrated in the following case: with the development of time, the deformation of surrounding rock starts from the sides of the arch waist at the junction of the composite stratum, while four arcs were derived and shear sliding occurred, resulting in overall collapse and destruction. (2) Following the support application, the space-time effect of the surrounding rock deformation was concentrated on the three stages of the interaction between the surrounding rock and the support, namely, the preliminary stage, the equilibrium process, and the instability state. The spatial effect was concentrated in the area where the surrounding rock was deformed and destroyed. The most severe area was the shallow surrounding rock, while the sub-violent area was the corner of the sidewall.

\section{Introduction}

The deformation of surrounding rock is closely related to time and space. The surrounding rock stress releases are apparently near the excavation face, which presents a noteworthy biased feature and time-space effect [1]. The socalled time effect is mostly related to the surrounding rock deformation; for example, before tunnel excavation, the released elastic-plastic deformation occurs inside the wall rock at the very moment of excavation, and wall rock creep deformation occurs after the excavation [2]. The space effect is mainly caused by the advance of excavation face, which causes the stress and strain of surrounding rock to change along the depth. The tunnel excavation influence on displacement of the space effect of excavation reaches three times the tunnel across, before, and after the tunnel surface $[2]$.

The special environment in which the deep rock mass was located led to the excavation presenting two core problems, namely, the reasonable excavation of the rock mass and the effective maintenance of the surrounding rock. Through the existing research, rich results in the deformation, fracture characteristics, laws, mechanisms, and control of deep rock masses have been achieved. Wang [3] believed that the characteristic energy factor was closely related to the characteristic scientific phenomena of deep rock mass in essence. Zhang et al. [4] extended the traditional block theory to analyze the life-cycle behavioristics (morphology, mechanics, kinematics and stability) of rock blocks during TBM (tunnel-boring machine) tunneling 
through TBM-block interaction consideration. Zareifard and Fahimifar [5] proposed that a fully analytical solution, for stresses and displacements around a tunnel, considering the effect of the damaged zone induced by the excavation impact, can quantify the real effect of a damage zone developed by a TBM excavation impact around a tunnel and its influence on the overall response of the tunnel. Chu et al. [6] believed that coupled analytical solutions, which take both the rock rheology and tunnel face advancement effects into consideration, can be used to predict the mechanical behavior of deep-buried circular lined tunnels in a soft rock mass. Lei et al. [7] considered that, under the complex and deeply buried condition, the excavation of a large section tunnel through digging from the top layer could significantly release the rock stress, while the rock displacement gently changed, which was conducive to the rock mass stability and structure security. Yang et al. [8] proposed that the damage rule of tunnel surrounding rock is controlled simultaneously by stress and lithological characteristics with numerical simulations by using the finite difference method in order to analyze the convergence deformation mechanism of tunnel excavating in composite strata. However, relatively few studies on the correlation between deep TBM tunnel support and surrounding rock stability exist. Individual studies have demonstrated that "bolting and shotcrete + secondary lining" and "segment + pea gravel + surrounding rock" were the main forms of TBM tunnel support [4], with a lack of sufficient theoretical analysis on the mechanical mechanism and behavior of "segment + surrounding rock."

In summary, for the surrounding rock stability control, the effect of time and space of the deformation of surrounding rock and supporting control mechanism, comprehensive "deep" and "TBM," "segment and surrounding rock," and other factors need to be discussed. Furthermore, in this article, the sand and paraffin cementation material composite formation simulation was utilized, through the custom-made machine experiment device to simulate TBM. This included digital photography measurement system, while the cross-sectional deformation of surrounding rock was observed, as well as concrete analysis of the characteristics of deformation and displacement of surrounding rock. Finally, deep composite formation under the TBM construction law of interaction among surrounding rock deformation, supporting structure, and surrounding rock interaction, along with the calculation methods of the support structural in TBM tunnel, was presented.

\section{Background}

It was assumed that the ground surface was flat and the depth of the tunnel constructed through TBM was $700 \mathrm{~m}$. The tunnel section was round and the diameter was $4 \mathrm{~m}$. Limited by model size, a certain stratum range was selected for study. The simulated object was a composite stratum composed of mudstone and argillaceous siltstone in Sichuan, China. The mechanical properties of the rock are presented in Table 1. The stratigraphic cross section is presented in Figure 1.

\section{Experimental Program}

3.1. Similitude Considerations. According to the similarity theory, combined with the characteristics of deep TBM construction, the similar criteria that met the requirements of this test were deduced as

$$
C_{E}=C_{\sigma}=C_{R}=C_{\rho} C_{L} .
$$

3.1.1. Geometric Parameters. The simulation test was based on the tunnel and model sizes, whereas the requirement was that the simulation range should be at least three times higher than the excavation space. A large-scale similar model was utilized to determine the geometric similarity ratio as $C_{L}=50$, while the actual dimensions of the entire model simulation were $20 \mathrm{~m} \times 15 \mathrm{~m} \times 5 \mathrm{~m}$. The geometrical dimensions of the tunnel model were calculated as follows: the tunnel diameter was $0.08 \mathrm{~m}$, the model body length was $0.4 \mathrm{~m}$, the model body height was $0.3 \mathrm{~m}$, and the model body width was $0.1 \mathrm{~m}$.

3.1.2. Density Parameters. The material content of the compacted sand and paraffin mixture was approximately $18 \mathrm{kN} / \mathrm{m}^{3}$, and the strength similarity ratio of similar materials was approximately 1.4 .

3.1.3. Strength and Modulus Parameters. The modulus of elasticity, compressive strength, and tensile strength of the model material were $1 / 70$ of the prototype material. The lithology indicators of the model could be obtained as presented in Table 2 .

3.2. Selection of Similar Materials and Model Making. Other tests have demonstrated that sand and paraffin cement as similar materials had the advantages of short production cycle, good elastoplasticity, stable mechanical properties, and low cost [9]. The deformation and rupture characteristics had a high similarity with the fracture characteristics of deep surrounding rock [9]. Therefore, in this test, a mixture of sand and paraffin was utilized to simulate a composite formation. According to the characteristics of different proportioning materials and the strength of the surrounding rock of the model determined above, the ratio of $100: 2$ was used to simulate the composite stratum composed of mudstone and argillaceous siltstone. A ratio of $100: 2.5$ was used to simulate a homogeneous formation consisting of argillaceous siltstone. The basic mechanical parameters of the sand and paraffin composite formation are presented in Table 3 [9].

3.3. Design of Roadheader Simulator and Model Box. The actual TBM is composed of a rock breaking mechanism, a propulsion mechanism, a rock loading mechanism, a steering adjustment mechanism, and a vacuuming and ventilation device, along with a supporting system [10]. The TBM equipment is too large, and the TBM construction 
TABLE 1: Mechanical properties of the rock.

\begin{tabular}{lccccc}
\hline Sequence number & Lithology & Compressive strength $(\mathrm{MPa})$ & Elastic modulus $E(\mathrm{GPa})$ & Poisson's ratio & Bulk weight $\left(104 \mathrm{~N} / \mathrm{m}^{3}\right)$ \\
\hline 1 & Mudstone & $14.3(2-54)$ & $2.24(2-20)$ & 0.35 & 18 \\
2 & Siltstone & $24(22-110)$ & $2.5(1.6-5.3)$ & 0.29 & 18 \\
\hline
\end{tabular}

The rock parameters were selected from the 1991 edition of the Manual of Rock Mechanics Parameters.

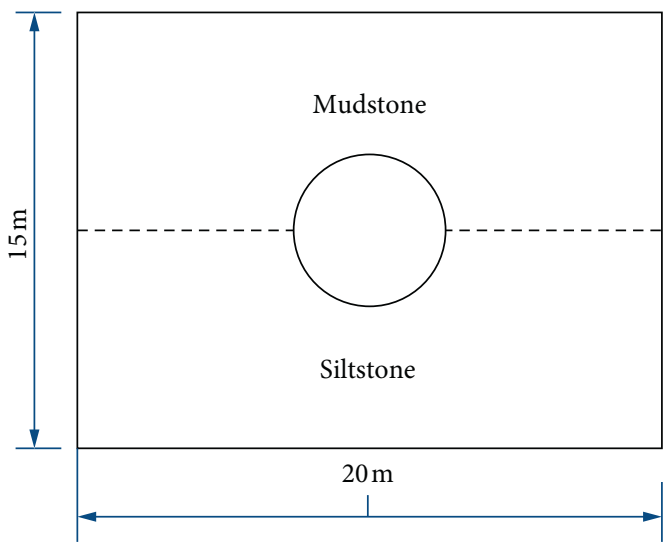

FIGURE 1: TBM tunnel mixed stratigraphic section.

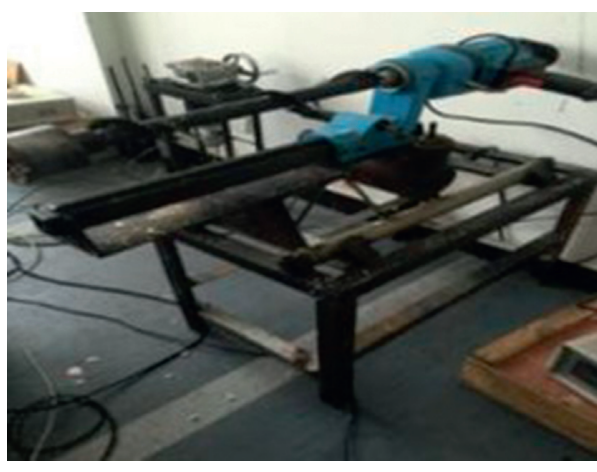

(a)

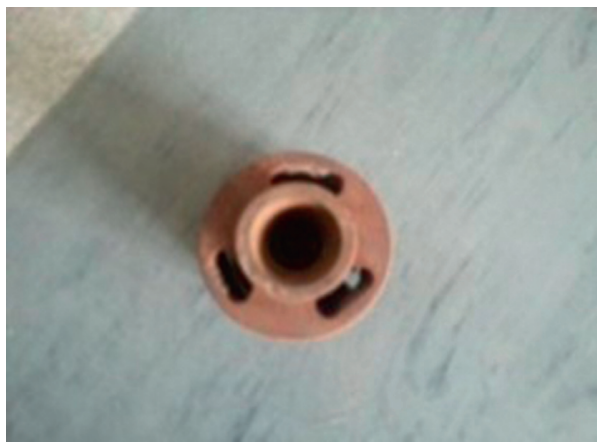

(c)

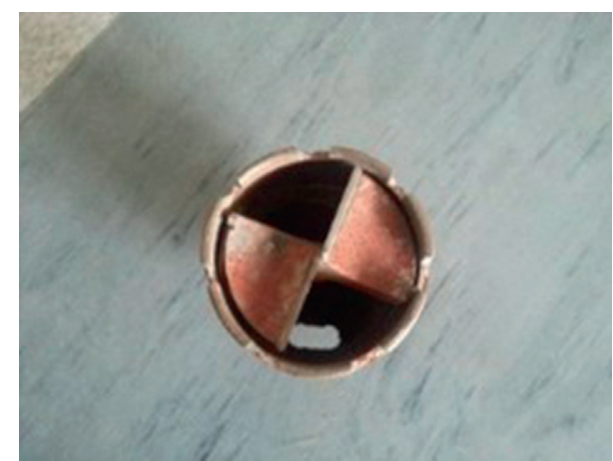

(b)

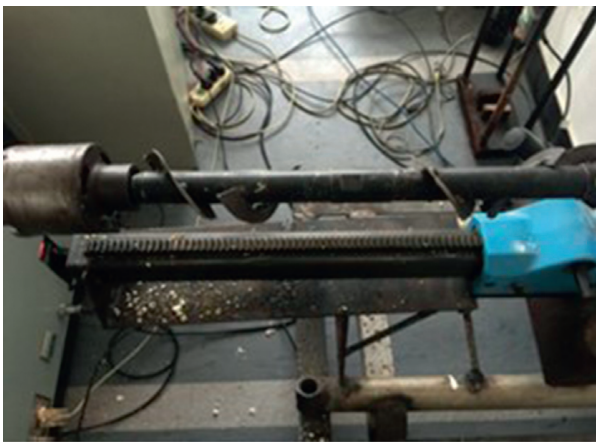

(d)

Figure 2: Schematic diagram of experimental device of TBM in structure simulation. (a) Front view. (b) Cutter head. (c) Shield and slag discharge. (d) Guide rail.

technology is too complicated. Through the TBM method, it is impossible to obtain good observation and test results for the rupture evolution of the surrounding rock deformation (including support structure), deformation mode, and time and space law of deformation and rupture, as well as stability control problems encountered during experiment. Also, the existing tunneling experimental device had a complicated structure and certain limitations.

The test model TBM should meet the basic working principle of TBM, while the basic performance parameters of the corresponding organizational structure should be similar to real TBM, to determine the basic composition and specific 
TABLE 2: Mechanical parameters of rock material transparent table model.

\begin{tabular}{lccccc}
\hline Sequence number & Lithology & Compressive strength $(\mathrm{MPa})$ & Elastic modulus $E(\mathrm{GPa})$ & Poisson's ratio & Bulk weight $\left(10^{4} \mathrm{~N} / \mathrm{m}^{3}\right)$ \\
\hline 1 & Mudstone & 0.18 & 0.032 & 0.35 & 2.5 \\
2 & Siltstone & 0.31 & 0.036 & 0.29 & 2.5 \\
\hline
\end{tabular}

TABLE 3: Basic mechanical parameters of sand and paraffin mixed strata.

\begin{tabular}{lccc}
\hline Sequence number & Compressive strength $(\mathrm{MPa})$ & Elastic modulus $(\mathrm{GPa})$ & Poisson's ratio \\
\hline Upper strata $(100: 2)$ & 0.18 & 32 & 0.29 \\
Lower strata $(100: 2.5)$ & 0.31 & 35.8 & 0.35 \\
\hline
\end{tabular}

size of the TBM model. According to the load size of the test loading system and the size of the model box, the "boring experimental device" was specially designed [11]. The main structure of the test system was as follows:

(1) Rack stabilizer: The main component was a frame. A rail was fixed on the frame. Also, a boring device was fixed on the frame.

(2) Driving device: It includes power unit, drill pipe, cutter head, and spiral blade. The roadheader was driven by a motor, and the tunneling speed was adjusted through a deceleration switch. The drill pipe could be adjusted according to the testing duration. A cutter head was fixed with the drill pipe at the front end, while the hollow drill pipe at the rear of the cutter head was axially extended and fixed with spiral blades, whereas the output shaft, the drill pipe, and the cutter head were on the same axis. The experimental device structure simulation is presented in Figure 2.

The model box consisted of a steel frame and a glass box. The glass box was made of 5 pieces of $15 \mathrm{~mm}$ thick transparent Plexiglas, bonded with glass adhesive. Peripheral steel frame was made by the former plate, as well as a back plate and approximately two sides with $8 \Phi 10 \mathrm{~mm}$ screws for assembly. When the model casing was completed, in order to satisfy the measurement technology of digital photography omnidirectional measurement requirements of its deformation, the rear panel 1 (cross) was removed, while the center position from the tunnel was joined with $\Phi 15 \mathrm{~mm}$ screws to improve its stability. The steel frame specification of the model box is presented in Figure 3.

3.4. Support Structure Scheme and Simulation Method. According to the technical data of the Daban rock tunnel [12], the average compressive strength of the pipe segment was 46.8-50.9 MPa. In view of the fact that the research object was a TBM tunnel of $700 \mathrm{~m}$ in depth, the required pipe segment had high compressive strength, while no relevant working condition data were available. Consequently, it was proposed to assume that the TBM pipe segment was poured as C75 high strength concrete. The compressive strength was $75 \mathrm{MPa}$, the weight was $25 \mathrm{kN} / \mathrm{m}^{3}$, the elastic modulus was $37.5 \mathrm{GPa}$, and the bulk density of gypsum was approximately $12 \mathrm{kN} / \mathrm{m}^{3}$. From the previous derivation of the similarity relationship, we could obtain the following: $C_{E}=C_{\sigma}=C_{R}=C_{r} C_{L}=114$; the compressive strength and elastic modulus of concrete pipe pieces were $1 / 114$ of the original type.

Due to the size limitation of the test platform, the similarity of joint and reinforcement as well as the influence of splicing mode on the pipe segment was not considered. Therefore, in this test, the similarity of compressive strength, elastic modulus, and Poisson's ratio of the supporting structure were mainly considered. Also, the pipe piece was considered as a whole under uniform stress. For the existing simulation of TBM pipe segment structure, the prototype material was mainly adopted. Lei et al. [13] and Wang [14] used different proportions of gypsum and water as the model material of tunnel lining or pipe segment for further research. Gypsum belongs to gas rigid cementitious materials, whose, through hydration hardening, stability time is short and solidification is fast, and it has the advantage of easy production. Moreover, the Poisson's ratio and concrete could well simulate the segment lining structure stress and strain characteristics, constituting a good simulation prototype material characteristic of brittle failure. Wang [14], based on the research data of proportion testing and engineering experience, selected three proportion schemes with mechanical properties for proportion testing, while 1074, 1075, and 1076 represented the proportion codes, respectively. Taking proportion number 1074 as an example, the volume ratio of gypsum to water was $1: 0.74$. Regarding the test materials with the above three combination ratios, the specimen making, the density testing, and the compression testing were conducted in turn. In addition, the physical and mechanical parameters of the three groups of similar lining materials were obtained, as presented in $\mathrm{Ta}$ ble 4 . Table 5 presents the mechanical parameters of lining and prototype materials [14].

According to Table 5, the final ratio was determined as follows: the volume ratio of gypsum to water was $1: 0.75$, signifying that the mass ratio was $1.35: 1$. Since the grinding fineness and water content of gypsum powder had significant influence on the physical and mechanical properties of materials, the water content for mixing was strictly controlled during testing, while gypsum powder of the same specification was used. The manufacturing of model pipe segments is presented in Figure 4. The dimensions of the model tube pieces were as follows: inner diameter of $50 \mathrm{~mm}$, outer diameter of $70 \mathrm{~mm}$, length of $100 \mathrm{~mm}$, and wall thickness of $10 \mathrm{~mm}$. During model casting, the support structure is embedded in the predetermined position. 


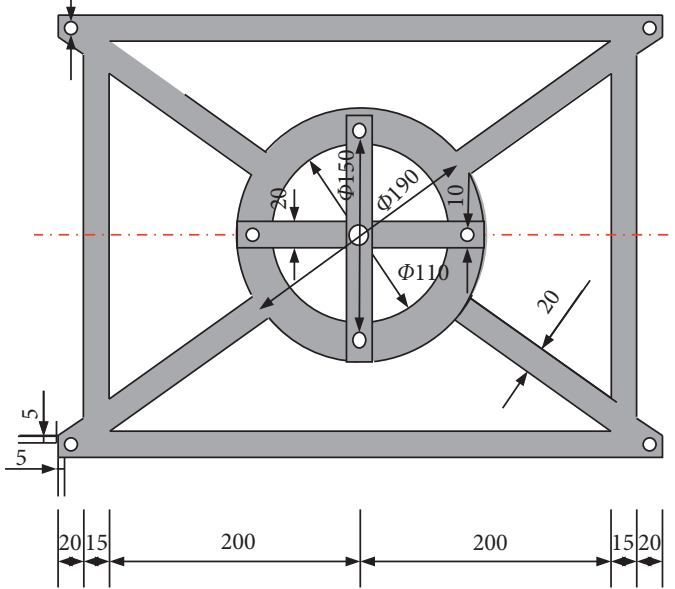

(a)

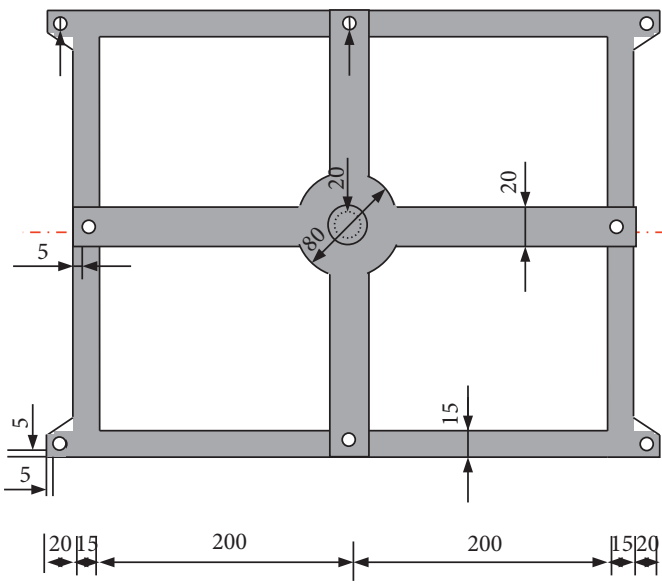

(c)

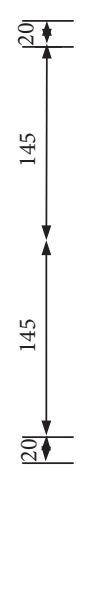

$\mid$

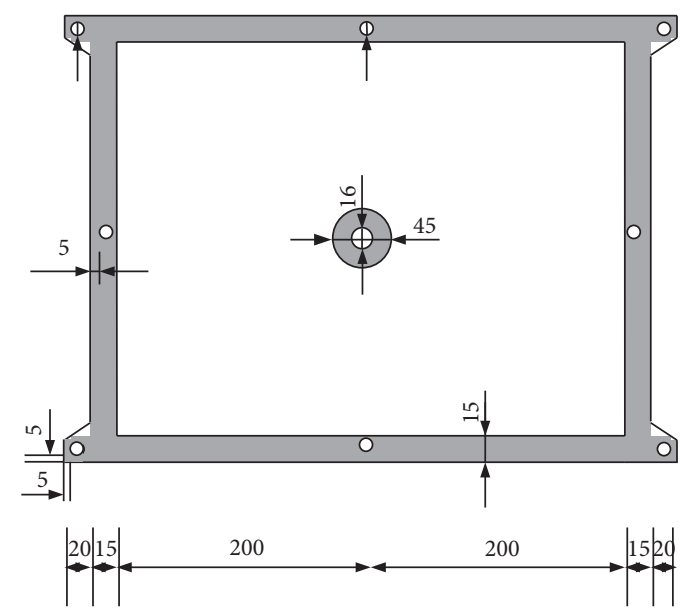

(b)

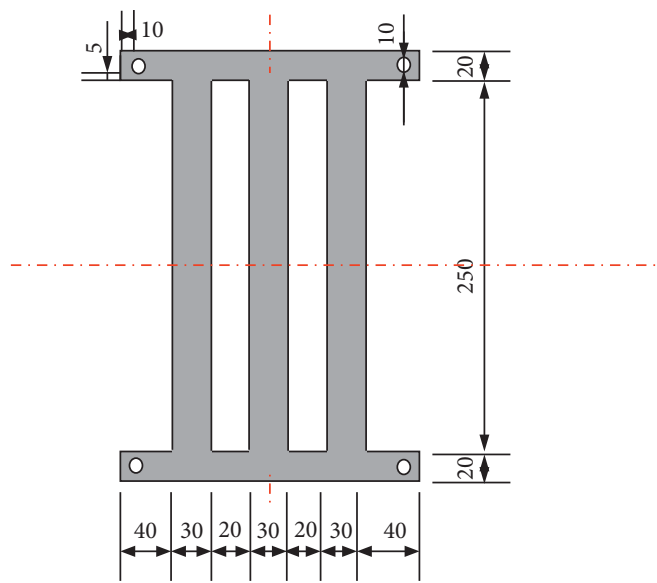

(d)

Figure 3: $400 \mathrm{~mm} \times 100 \mathrm{~mm} \times 300 \mathrm{~mm}$ model steel frame. (a) Front panel. (b) Back plate I. (c) Back plate II. (d) Side plate.

TABLE 4: Mixture ratios and properties of admixture of sand and olefin.

\begin{tabular}{lccc}
\hline & Compressive strength $(\mathrm{MPa})$ & Elastic modulus $(\mathrm{GPa})$ & Unit weight $\left(10^{4} \mathrm{~N} / \mathrm{m}^{3}\right)$ \\
\hline \multirow{2}{*}{ Prototype model } & 75 & 37.5 & 25 \\
& 0.72 & 0.37 & 12 \\
\hline
\end{tabular}

TABle 5: Mechanical properties of the different segment and similarity ratios [14]

\begin{tabular}{cccccccc}
\hline Code & Gypsum & Water & $\begin{array}{c}\text { Elasticity modulus } \\
(\mathrm{GPa})\end{array}$ & $\begin{array}{c}\text { Volume-weight }(\mathrm{kN} / \\
\left.\mathrm{m}^{3}\right)\end{array}$ & $\begin{array}{c}\text { Compressive strength } \\
(\mathrm{MPa})\end{array}$ & $\begin{array}{c}\text { Similarity ratio } \\
C_{1}\end{array}$ & $\begin{array}{c}\text { Similarity ratio } \\
\mathrm{C}_{2}\end{array}$ \\
\hline 1074 & 57.5 & 42.5 & 0.70 & 12.12 & 0.73 & 1.096 & 0.970 \\
1075 & 57.1 & 42.9 & 0.72 & 12.58 & 0.81 & 1.025 & 0.978 \\
\hline
\end{tabular}

3.5. Surrounding Rock Stress and Displacement Measurement Method. Stress, strain, displacement, and load were the main measured parameters in the geomechanical model tests. In order to effectively observe and analyze the spatial and temporal evolution rules of surrounding rocks, in view of the size of this test model and the development of internal stress in surrounding rocks of the tunnel, the test data were obtained through buried Earth pressure boxes. In this tests, effective data measurements were conducted at the measuring points of the model by the static strain gauge $\mathrm{DH}$ $3818+$ resistance miniature Earth pressure box $(d=17 \mathrm{~mm}$, $h=9 \mathrm{~mm}$ ). The Earth pressure box and the corresponding layout are presented in Figure 5. The box is mainly arranged at approximately $5 \mathrm{~cm}$ away from the top, the bottom, and the boundaries of left and right sidewalls of the tunnel. The main function of the model was to record the deformation data, such as transverse horizontal stress and vertical stress during loading. 


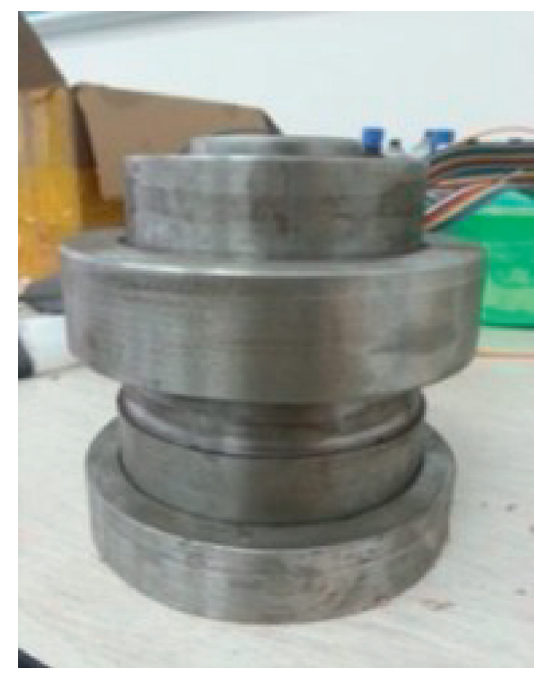

(a)

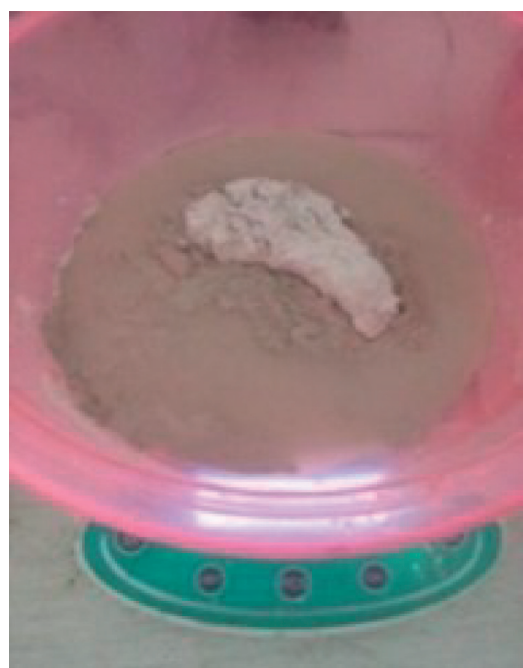

(b)

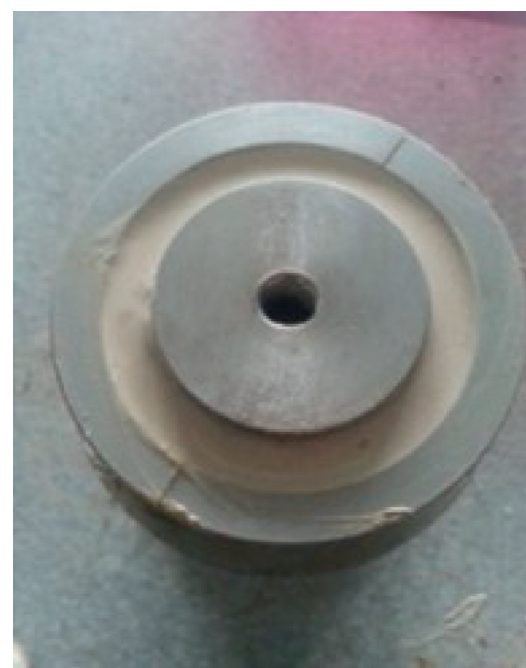

(c)

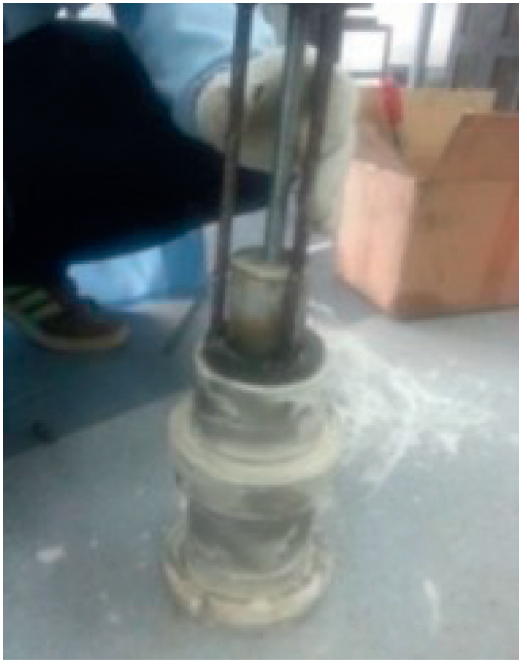

(d)

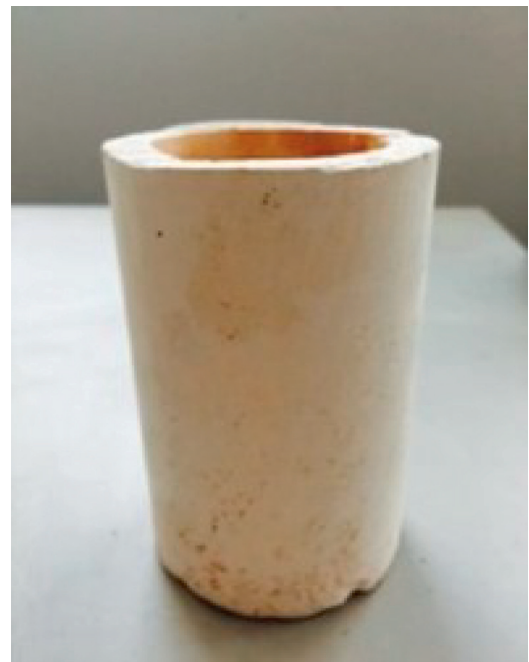

(e)

Figure 4: Schematic diagram of segment mode. (a) Mould. (b) Weighing. (c) Pouring model. (d) Removing the mould. (e) Model of the segment.

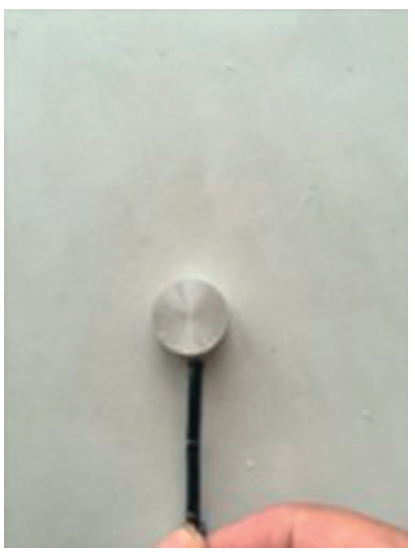

(a)

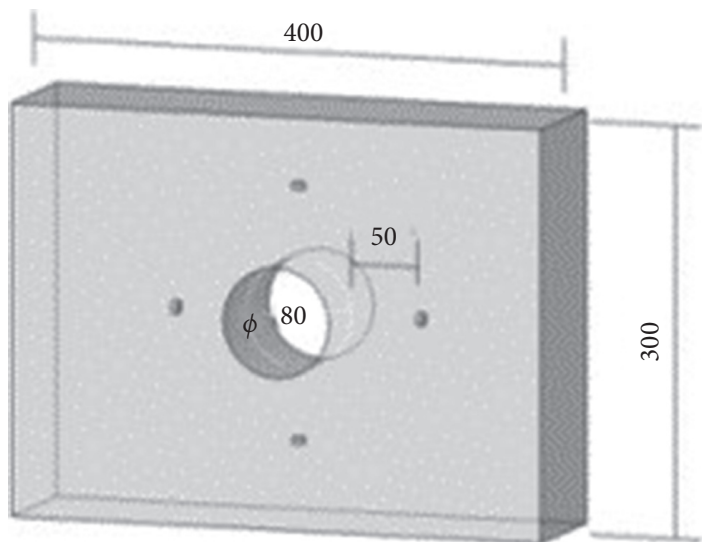

(b)

Figure 5: Earth pressure cells and their schematic layout. (a) Miniature Earth pressure chamber. (b) Schematic diagram of Earth pressure box layout. 
For the surface displacement and strain of surrounding rock of tunnel, the digital photographic measurement technique of noncontact measurement method was adopted.

3.6. Support Structure Stress Measurement Method. In order to measure the change of internal stress of the support structure, the unit strain gauge with three right-angle strain flowers was used during testing, as presented in Figure 6(a). Each strain rosette contained three strain gauges, with spacing of $45^{\circ}$. A total of nine strain gauges were used. Following the support structure construction, the strain flowers were fixed to the surface of the support structure. Subsequently, the wires are connected, sealed with sealant, while the strain gauge of dh-3818 was connected through the wires (Figure 6(b)). Each group of strain flowers recorded the positive strain of the top, bottom, and two sidewalls of the support structure, respectively. According to the strain values of strain gauges 1,2 , and 3 on the strain brick affected by stresses from different directions, the maximum and minimum principal stress values, along with the maximum shear stress, could be obtained from the following equation:

$$
\sigma_{\max }=\frac{E}{2}\left[\frac{\varepsilon_{1}+\varepsilon_{2}}{1-\mu_{0}}+\frac{1}{1+\mu_{0}} \sqrt{\left(\varepsilon_{1}-\varepsilon_{3}\right)^{2}+\left(2 \varepsilon_{2}-\varepsilon_{1}-\varepsilon_{3}\right)^{2}}\right],
$$

$$
\sigma_{\min }=\frac{E}{2}\left[\frac{\varepsilon_{1}+\varepsilon_{2}}{1-\mu_{0}}-\frac{1}{1+\mu_{0}} \sqrt{\left(\varepsilon_{1}-\varepsilon_{3}\right)^{2}+\left(2 \varepsilon_{2}-\varepsilon_{1}-\varepsilon_{3}\right)^{2}}\right],
$$

$$
\tau_{\max }=\frac{E}{2\left(1+\mu_{0}\right)} \sqrt{\left(\varepsilon_{1}-\varepsilon_{3}\right)^{2}+\left(2 \varepsilon_{2}-\varepsilon_{1}-\varepsilon_{3}\right)^{2}},
$$

where $\sigma_{\max }$ is the maximal principal stress; $\sigma_{\min }$ is the minimum principal stress; $\tau_{\max }$ is the maximum shear stress; $E$ is the elastic modulus of concrete segments; $\mu_{0}$ is the Poisson's ratio of concrete segments; and $\varepsilon_{1}, \varepsilon_{2}$, and $\varepsilon_{3}$ are the strain values.

3.7. Tunnel Excavation and Loading Design. When the tunnel model was completed, the excavation load tests of the tunnel could be carried out, as presented in Figure 7. The specific steps were as follows.

3.7.1. Testing Preparation. Prior to testing initiation, it was first ensured that the constant loading pressure on the top surface of the model was $10 \mathrm{kN}$. Consequently, camera lamps were set on both sides of the observation surface of the model, to ensure that the observation surface would always be showered with uniform light during testing. Simultaneously, a high-resolution digital camera was placed at approximately $0.5 \mathrm{~m}$ in front of the observation surface of the model, while the parameters of the digital camera were adjusted to produce clear images.

3.7.2. Tunnel Excavation (Unsupported Modes). In the similarity theory, the relation between time similarity ratio and geometric similarity ratio is a square root relation. Consequently, the similarity ratio between prototype and model was 7.07. The existing TBM daily footage had significant relationship with tunnel engineering geology and TBM type selection. The basic daily footage interval was $10-100 \mathrm{~m} /$ day, and the daily working time was $12 \mathrm{~h}$, which was divided into pure tunneling time $(6 \mathrm{H})$ and equipment maintenance + support time $(6 \mathrm{H})$. The selected TBM daily footage was $50 \mathrm{~m} /$ day. It could be observed that the net tunneling footage per hour of the TBM was $8.3 \mathrm{~m} / \mathrm{h}$. Therefore, it could be concluded that the excavation time was $5 \mathrm{~min}$, while the excavation method was completed once.

3.7.3. Tunnel Loading. The top of the model was loaded in stages (each load increased by $3 \mathrm{kN}$ for $15 \mathrm{~min}$ ) until the rock mass around the tunnel failed. During loading, a computercontrolled digital camera was also used for automatic image collection, with a collection frequency of $10 \mathrm{~s}$.

3.8. Digital Photographic Measurement Technology. Digital photographic measurement technology is a new method for measuring deformation field of geotechnical test model, which is composed of PhotoInfor software and PostViewer software. PhotoInfor is mainly responsible for the deformation analysis of digital images, while PostViewer is responsible for the graphical drawing and further statistical analysis of the analysis results [15]. Following testing, PhotoInfor software was used for image format conversion (RAW to BMP) and image analysis, while ANSYS was used for the unit division and import. Due to the short excavation time, the excavation had insignificant influence on the surrounding rock deformation.

\section{Evolution Law of Deformation and Fracture of Surrounding Rock of Composite Stratum}

Following the completion of tunnel excavation, the top of the tunnel was loaded at a rate of $10 \mathrm{~N} / \mathrm{s}$, as presented in Figure 8. The unsupported model went through five stages from loading to failure, while the ultimate bearing capacity of surrounding rock was $0.55 \mathrm{MPa}$. Figure 9 presents the main test image of the unsupported model.

4.1. Vertical Displacement. Figure 10 presents the vertical displacement cloud diagram without support model under different loads. It could be observed that, under different loads, the vertical displacement of the rock mass at the top of the tunnel always reached its maximum value near the arch, whereas, from this position, it gradually decreased to the depth of the surrounding rock. At the beginning of deformation ( $0.25 \mathrm{MPa}-0.40 \mathrm{MPa})$, the vertical displacement of the tunnel had no apparent characteristics and rules. As the top load increased $(0.40 \mathrm{MPa}-0.52 \mathrm{MPa})$, the vertical displacement of the rock mass at the top and bottom of the tunnel gradually increased. When the top load reached $0.55 \mathrm{MPa}$ 


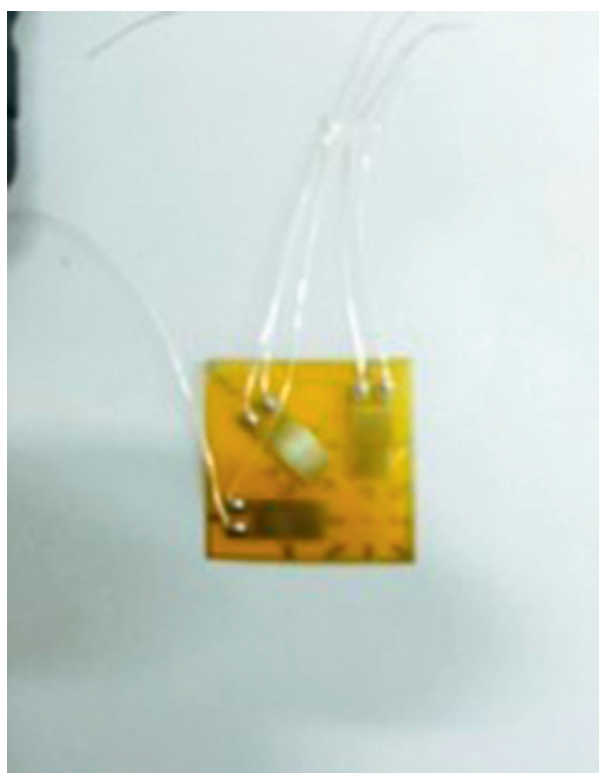

(a)

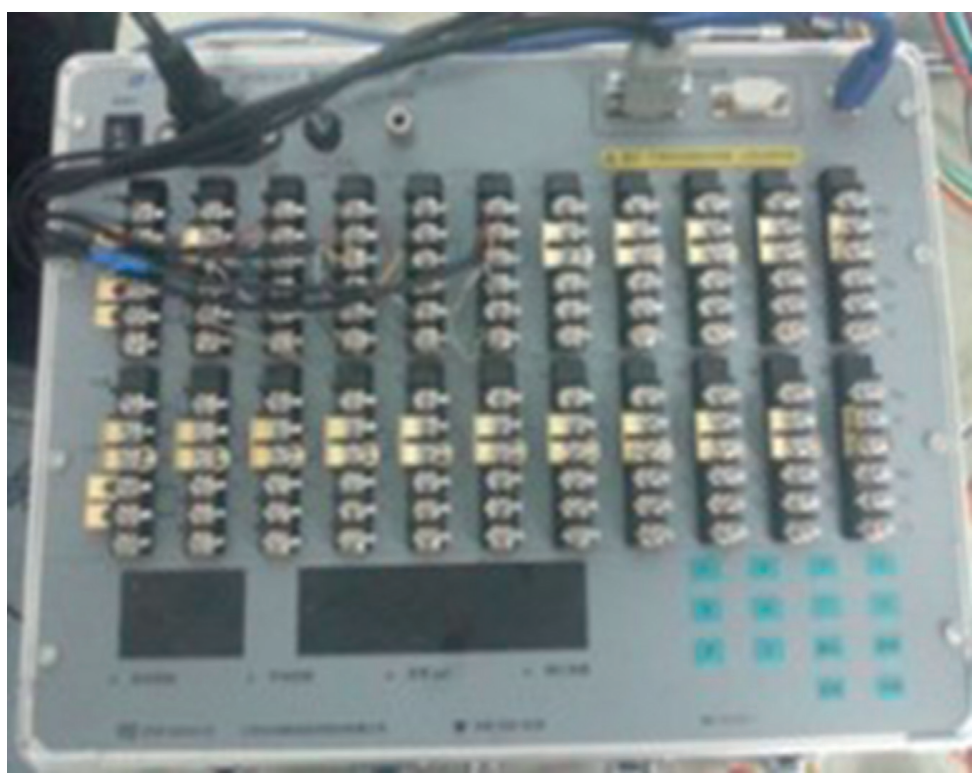

(b)

FIGURE 6: Strain flower and static strain gauge as used during testing. (a) Strain rosette. (b) DH-3818 strain gauge.

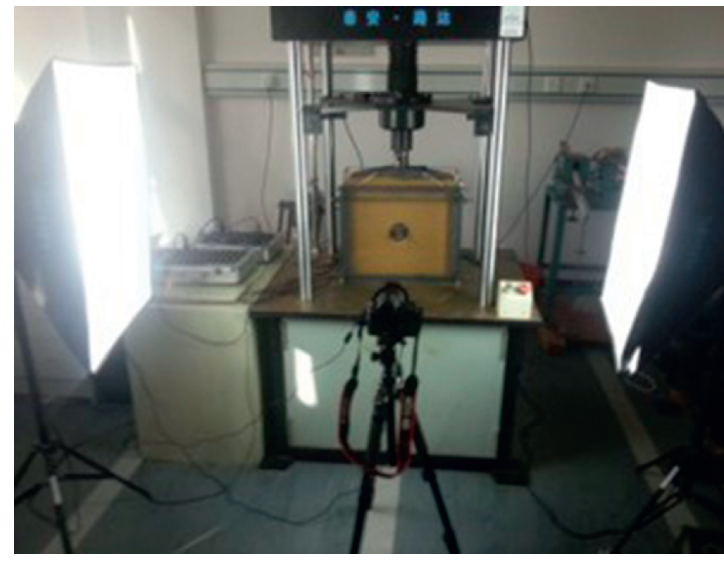

(a)

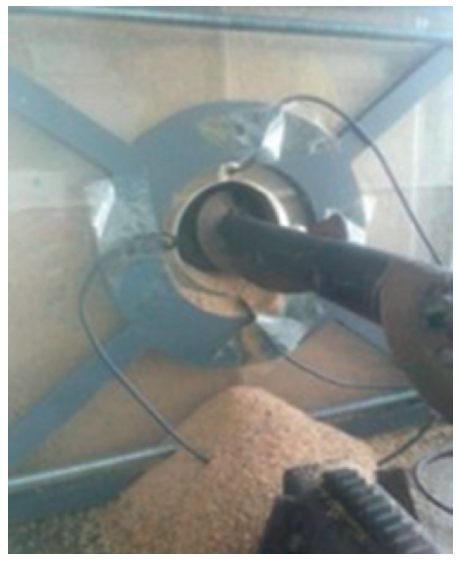

(b)

Figure 7: Roadway excavation and loading. (a) Test preparation. (b) Modeled excavation.

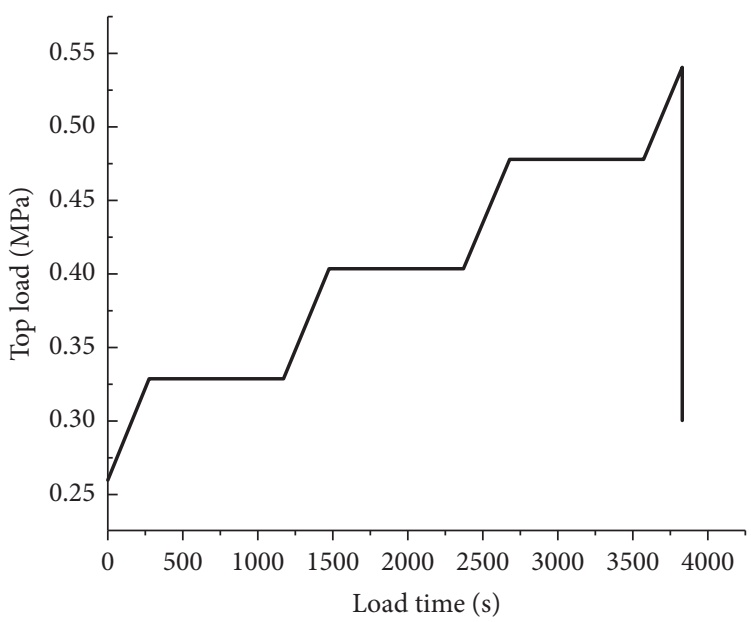

FIGURE 8: Curve of top load versus time for unsupported model. 


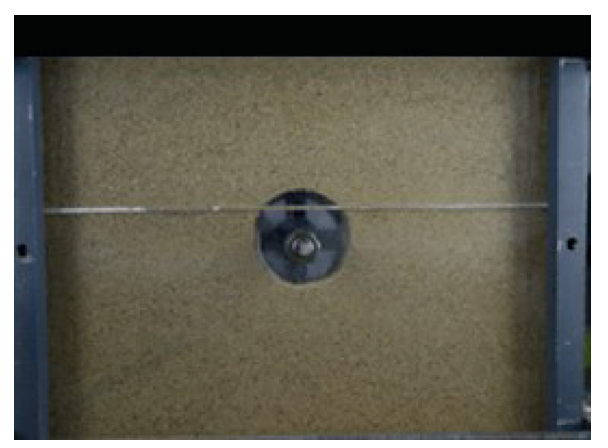

(a)

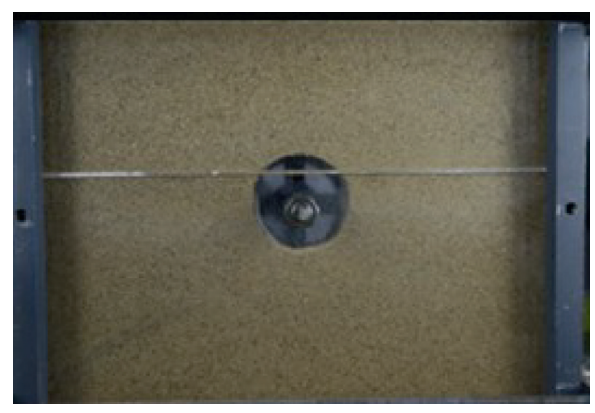

(c)

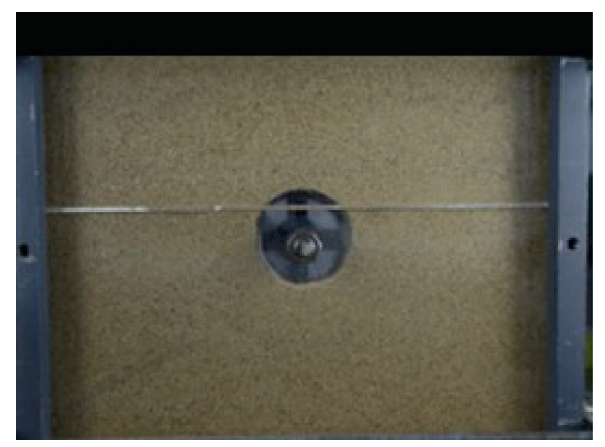

(b)

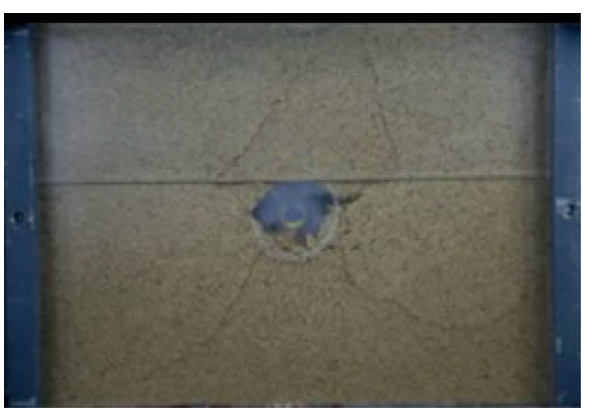

(d)

FIgURE 9: Main test image of unsupported mode. (a) $0.25 \mathrm{MPa}$. (b) $0.40 \mathrm{MPa}$. (c) $0.52 \mathrm{MPa}$. (d) $0.55 \mathrm{MPa}$.

(Figure 10(f)), the surface displacement field of the tunnel presented an $x$-shaped fracture feature. The change of tunnel displacement was highlighted by the maximum at the top, and it decreased successively from the top to the two sidewalls.

4.2. Horizontal Displacement. The cloud diagram of horizontal displacement distribution of the unsupported model under different loads is presented in Figure 11. It is shown that, at the beginning of the deformation $(0.25 \mathrm{MPa}$ to $0.40 \mathrm{MPa})$, the displacement of tunnel occurred with no apparent change. As the top load increased (0.40 MPa to $0.52 \mathrm{MPa}$ ), without the supporting model horizontal displacement of surrounding rock mass mainly in two locations near the wall, the horizontal displacement increased gradually and quickly to tunnel marginal development (Figures 11(b)-11(e)); when the tunnel roof load was $0.55 \mathrm{MPa}$, the horizontal displacement of rock mass mainly occurred in $X$ to left and right sides of the tunnel (Figure 11(f)), which further demonstrated that as the top load increased, the roof rock mass of the tunnel might slide along two arcs of the two sides of the tunnel, leading to tunnel instability and failure. Through analysis, the reason might be that as the tunnel roof load increased, the rupture of the two sidewalls of rock burst into gradual depth. Also, the degree of rupture range gradually increased, while the part of the bearing capacity of rock mass reduced, leading the rock mass at the waist place of the arch tunnel to instability. Moreover, similar slope instability phenomenon occurred.

4.3. Maximum Shear Strain. Maximum shear strain constitutes one of the important indexes reflecting the deformation and fracture status of surrounding rock. The cloud chart of maximum shear strain without support model is presented in Figure 12. When the top load of the model was below $0.4 \mathrm{MPa}$, the maximum shear strain of rock mass around the tunnel was not apparent, whereas when the top load of the model was higher than $0.4 \mathrm{MPa}$, the maximum shear strain displayed a sudden increase, which was the maximum at the arched waist of the two sidewalls. This indicated that the rock mass around the tunnel mainly broke at the two sidewalls. The maximum shear strain of the surrounding rock always occurred near the arched waist on both sides of the tunnel, while the shear strain of the rock mass at other locations was quite low.

4.4. Quantitative Analysis of Displacement Evolution of Surrounding Rock. Four measuring points were selected from the analysis images of the top, the left wall, the right wall, and the bottom of the tunnel for quantitative analysis of the total displacement of the measuring points, as presented in Figure 13.

As the top load increased, before the top load of $0.33 \mathrm{MPa}$, the displacement change of the surrounding rock roof, the bottom, and the two sidewalls was not apparent, and the displacement change trend was consistent. After $0.33 \mathrm{MPa}$, the total displacement of surrounding rock of the top, bottom, and both sides of the tunnel displayed an apparent differentiation and growth, which demonstrated that although the total displacement of surrounding rock of the top, bottom, and both sides of the tunnel gradually increased, the displacement of surrounding rock at the top of the tunnel was quite apparent than at the bottom and the two sides. The displacement at the bottom of the composite formation changed slightly during the entire loading process. When the wall rock was finally destroyed $(0.55 \mathrm{MPa})$, the total displacements of the measuring 


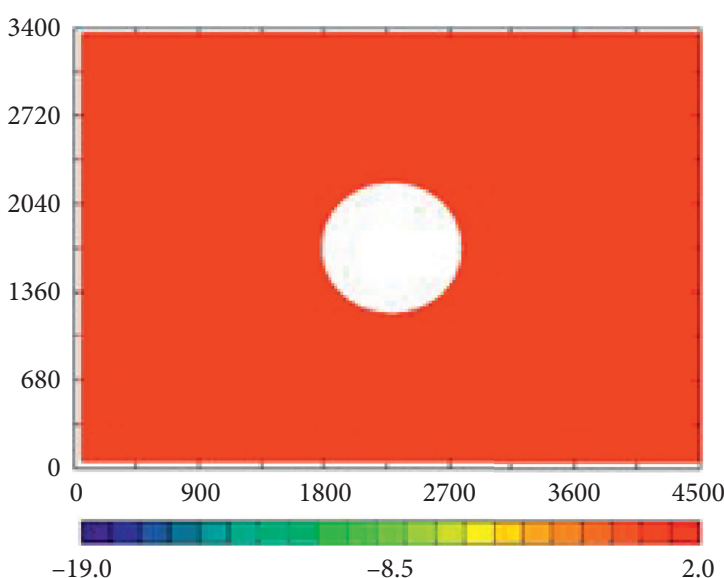

(a)

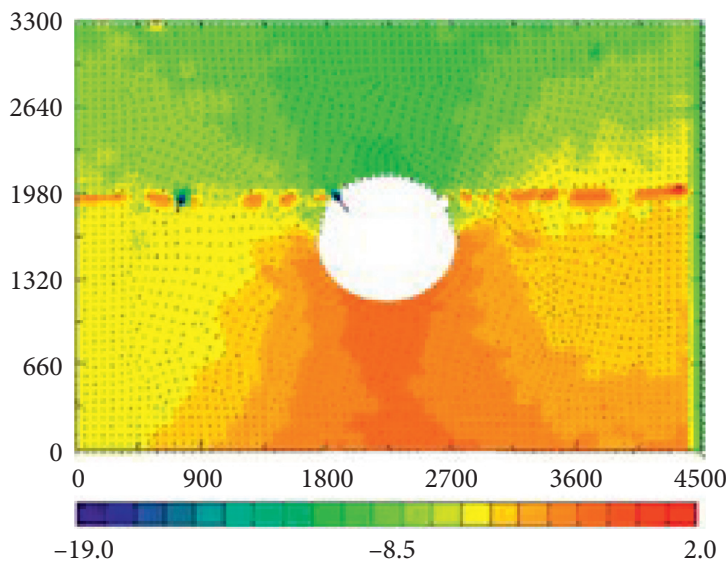

(c)

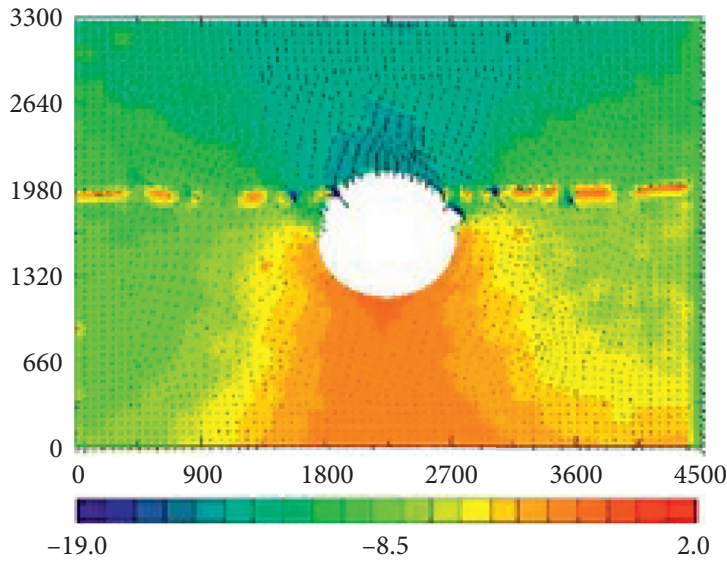

(e)

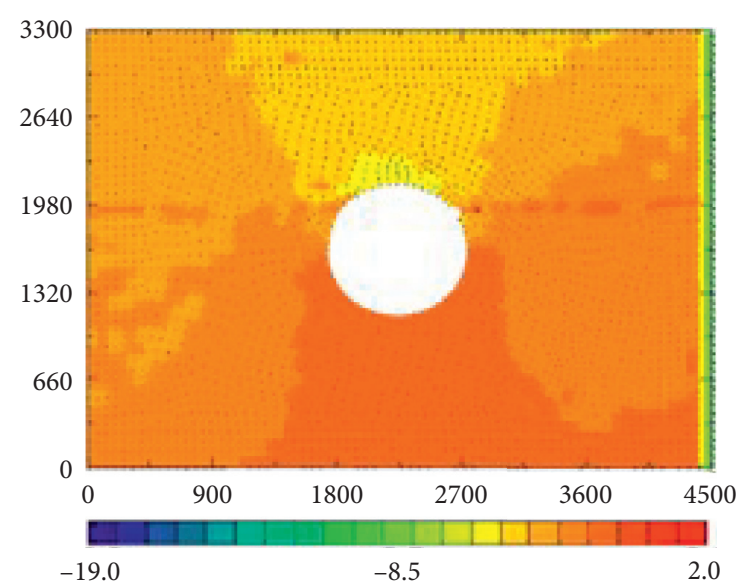

(b)

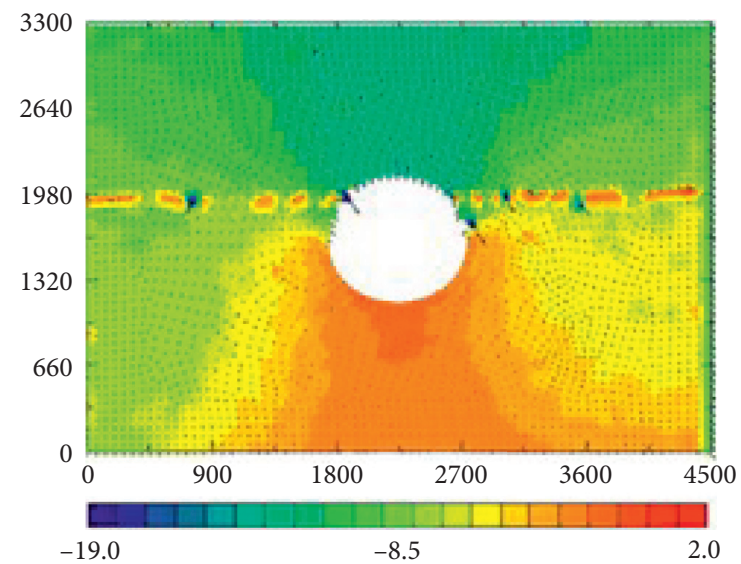

(d)

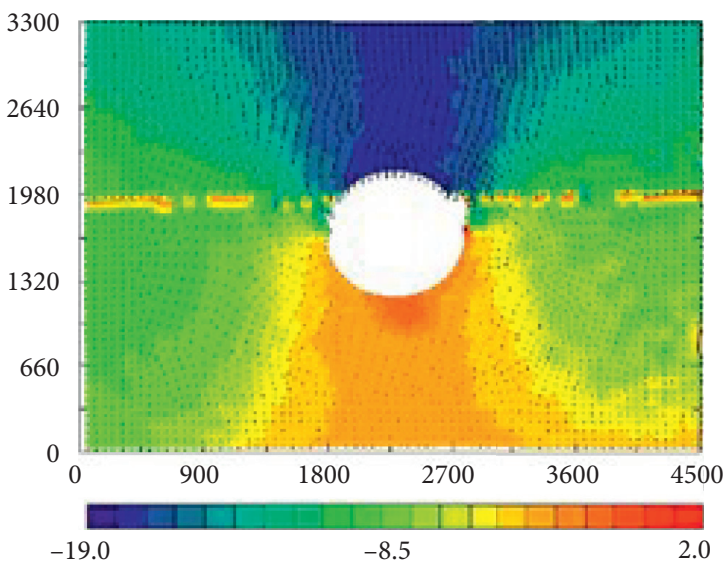

(f)

Figure 10: Vertical displacement cloud map of unsupported modes. (a) $0.25 \mathrm{MPa}$. (b) $0.40 \mathrm{MPa}$. (c) $0.47 \mathrm{MPa}$. (d) $0.51 \mathrm{MPa}$. (e) $0.52 \mathrm{MPa}$. (f) $0.55 \mathrm{MPa}$.

point on the top of the wall rock were $18.03 \mathrm{~mm}, 11.41 \mathrm{~mm}$, $13.80 \mathrm{~mm}$, and $3.16 \mathrm{~mm}$, respectively.

4.5. Stress Evolution of Surrounding Rock. The stress evolution of surrounding rock is presented in Figure 14. It could be observed that, as the top load increased, the values of the top, the bottom, and the two walls of the surrounding rock presented a relatively stable increase in the initial stage of loading. Although the surrounding rock stress of the rock mass at the top and bottom of the tunnel gradually increased, the change of the surrounding rock stress of the two walls of the tunnel was significantly apparent than at the bottom and top. When the top load 


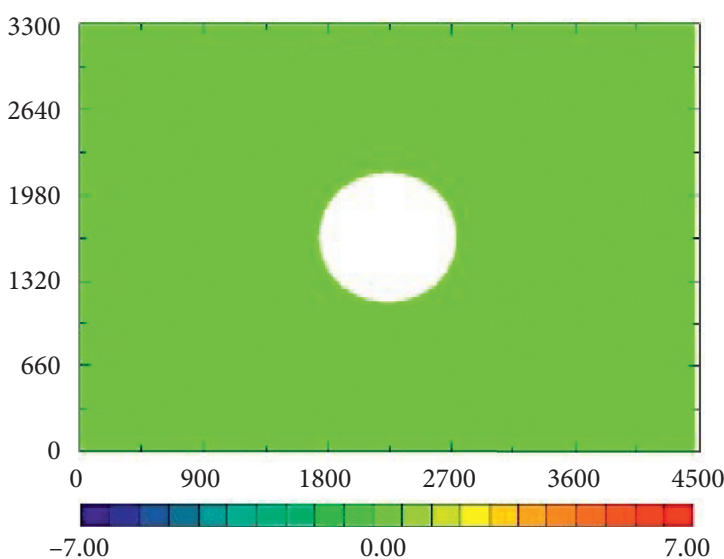

(a)

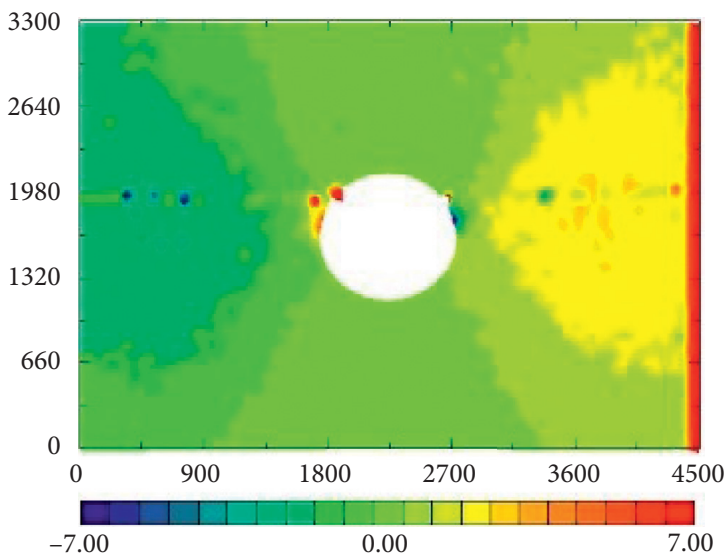

(c)

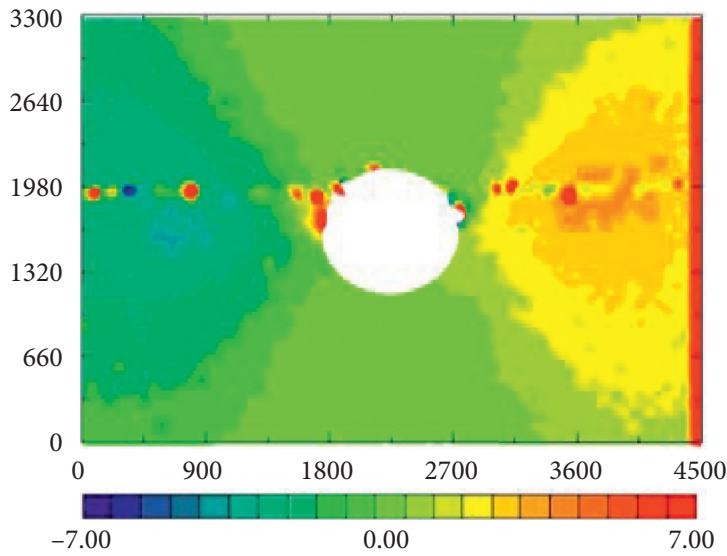

(e)

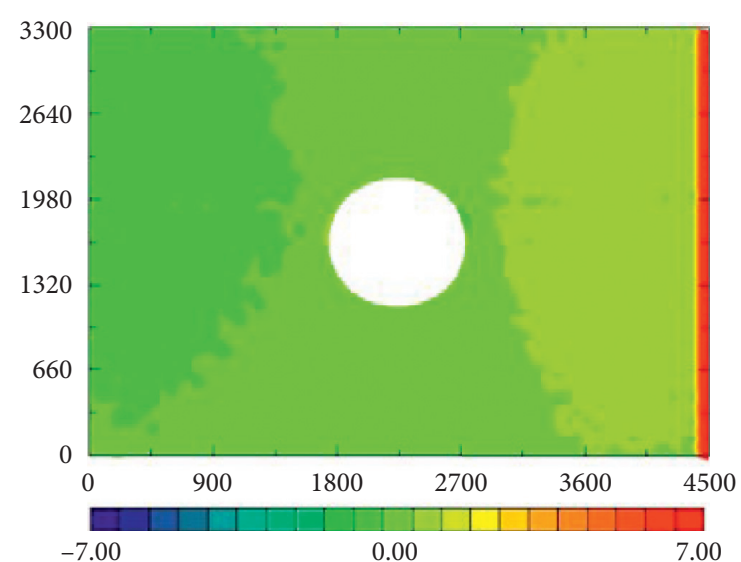

(b)

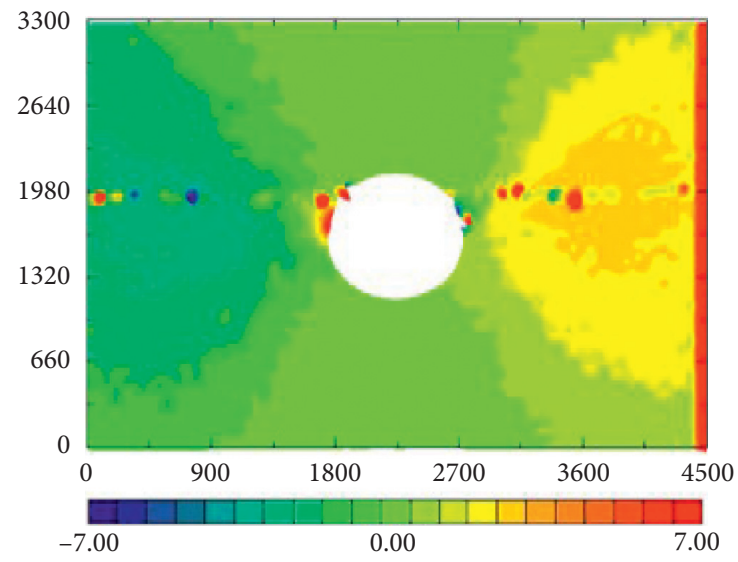

(d)

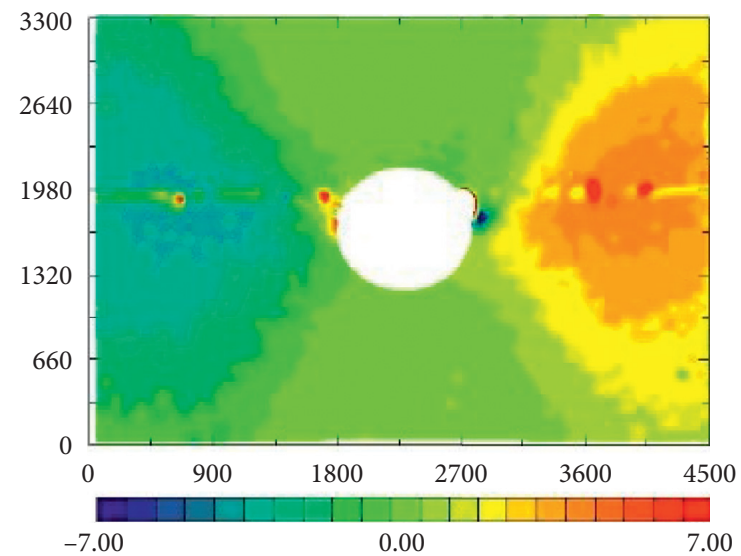

(f)

Figure 11: Horizontal displacement cloud map of unsupported model. (a) $0.25 \mathrm{MPa}$. (b) $0.40 \mathrm{MPa}$. (c) $0.47 \mathrm{MPa}$. (d) $0.51 \mathrm{MPa}$. (e) $0.52 \mathrm{MPa}$. (f) $0.55 \mathrm{MPa}$.

reached $0.4 \mathrm{MPa}$, the surrounding rock stress value of the top and bottom walls presented apparent differentiation and growth, while the stress curve of the two walls demonstrated a characteristic and law of steep increase. When the top load was loaded to the limit force of the surrounding rock of $0.55 \mathrm{MPa}$, the surrounding rock stress increased further, while the horizontal stress of the two walls was destroyed after reaching the peak.

\section{Space-Time Effects of Deformation and Rupture of Surrounding Rock in Composite Stratum}

After the support model loaded the ground stress, it continued to load the top, and the loading rate was $10 \mathrm{~N} / \mathrm{S}$, as presented in Figure 15. The position of the top load dropped instantaneously with time, indicating that the supporting 


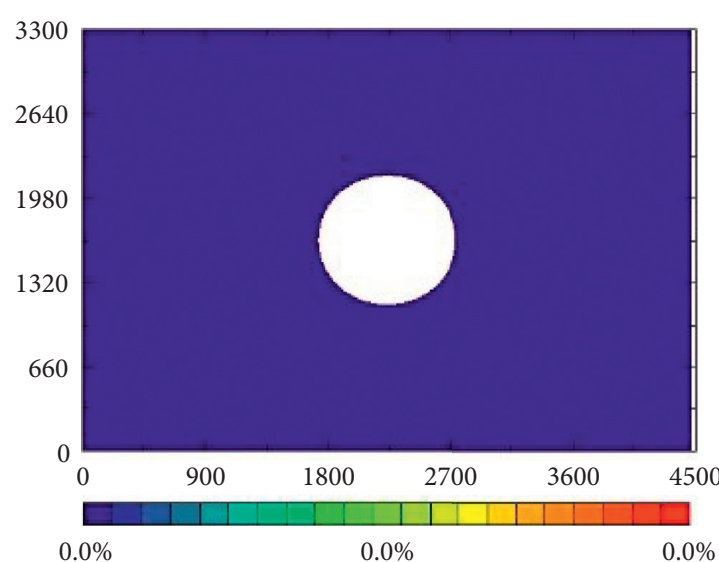

(a)

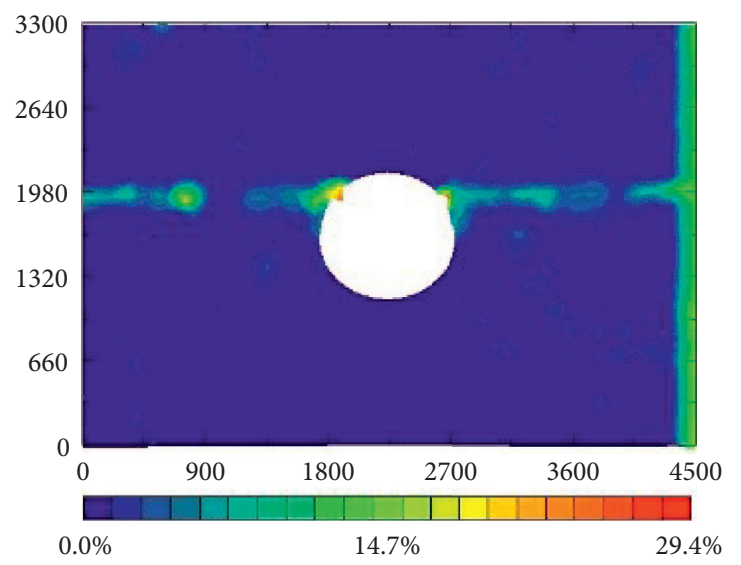

(c)

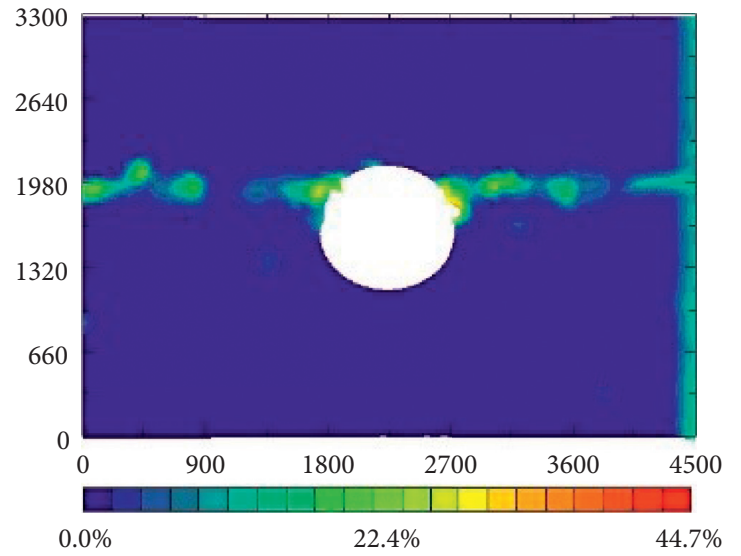

(e)

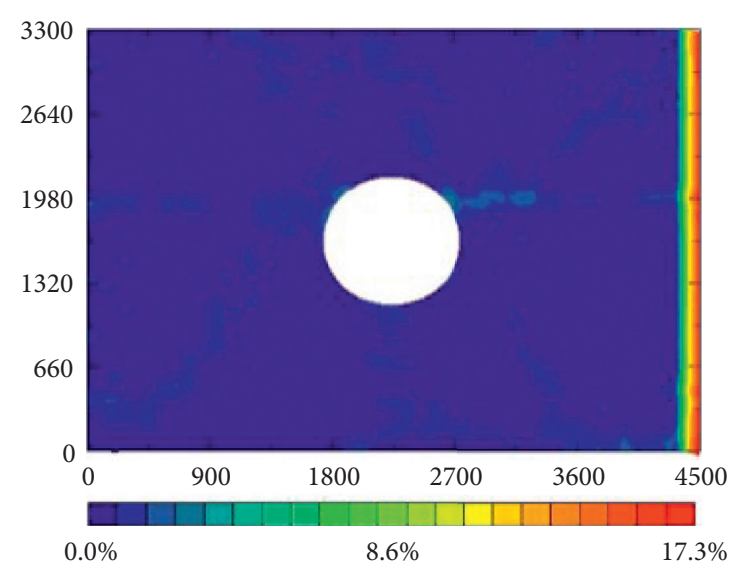

(b)

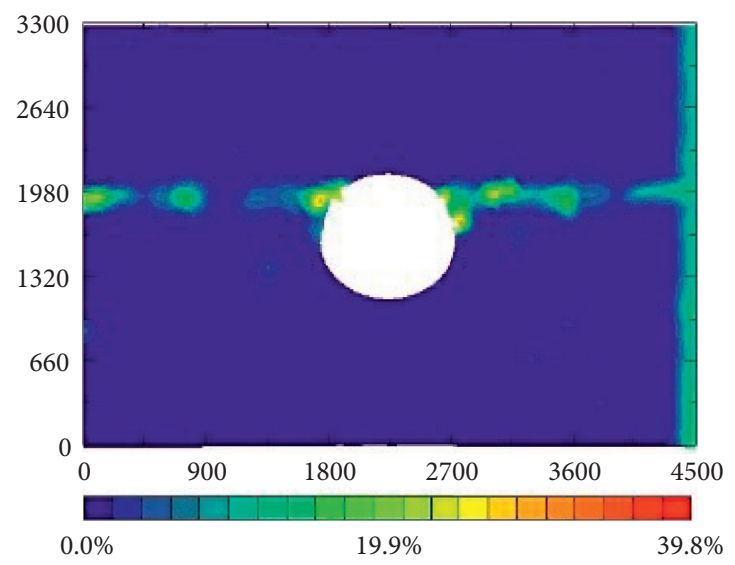

(d)

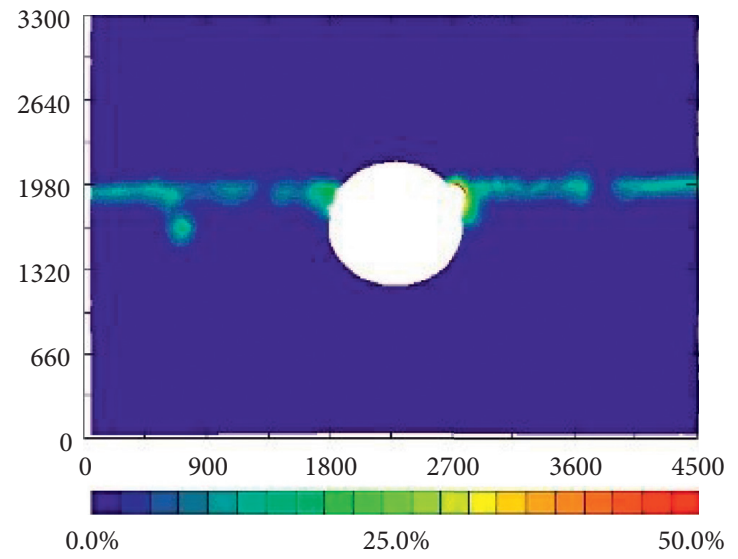

(f)

FigURE 12: Horizontal displacement cloud map of unsupported model. (a) $0.25 \mathrm{MPa}$. (b) $0.40 \mathrm{MPa}$. (c) $0.47 \mathrm{MPa}$. (d) $0.51 \mathrm{MPa}$. (e) $0.52 \mathrm{MPa}$. (f) $0.55 \mathrm{MPa}$.

structure might be slightly damaged by the crack. When the top load reached $0.67 \mathrm{MPa}$, the surrounding rock was eventually destroyed. Figure 16 presents the main test image of the supported model.

5.1. Vertical Displacement. Figure 17 presents the vertical displacement cloud diagram with support model under different loads. In the early stage of combined action of surrounding rock and support $(0.25 \mathrm{MPa}-0.32 \mathrm{MPa})$, the vertical displacement increased slowly, and no major mutation or inflection point existed. Through combination of surrounding rock and supporting medium $(0.48 \mathrm{MPa}$ to $0.58 \mathrm{MPa}$ ), as the top of the load increased, the maximum vertical displacement was evenly distributed in the shallow rock mass. From the shallow to the deep rock mass, layers of 


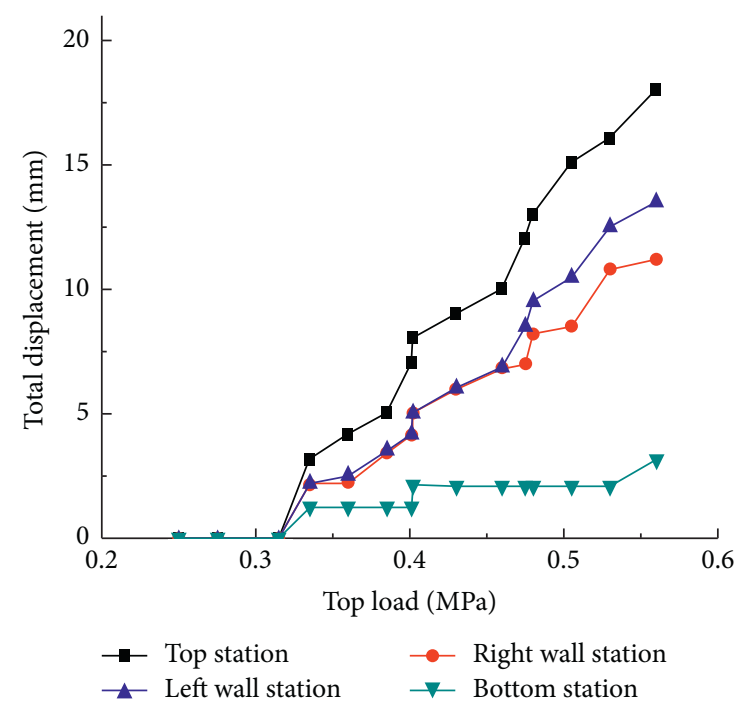

FIgURE 13: Unsupported model load-displacement curve.

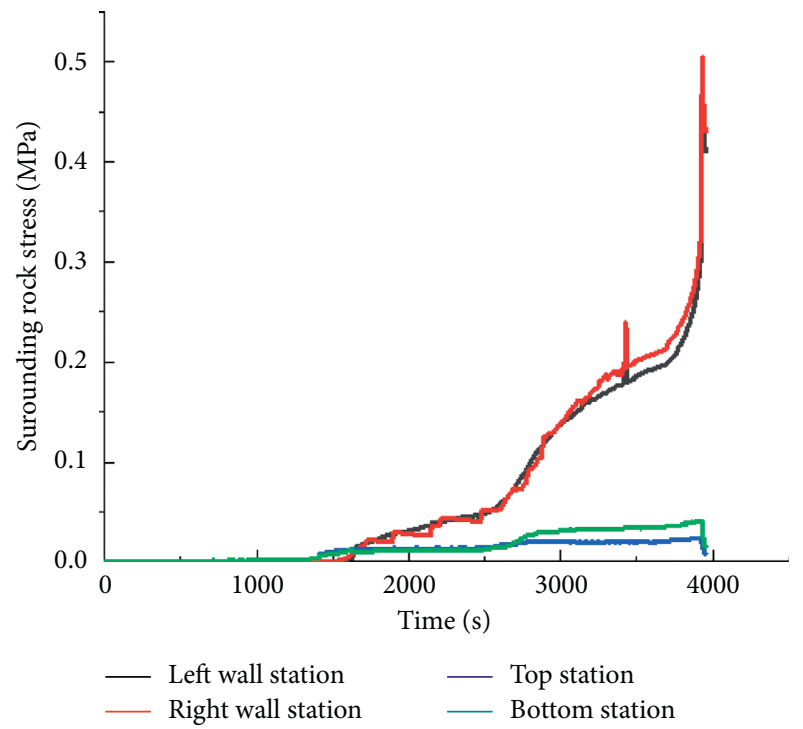

FIGURE 14: Stress time variation curve of surrounding rock in ordinary mixed strata.

rock mass existed, following a relatively uniform decline; this demonstrated that shallow surrounding rock looseness damage occurred, with support resistance, forming stable bearing structure, under the action of shallow and deep bearing area of coordinating role, to enhance the stability of deep surrounding rock deformation. Prior to the supporting structure failure $(0.67 \mathrm{MPa})$, the vertical displacement of the top of the model presented a "block-like" shape, indicating that the shallow surrounding rock was damaged. Both sides of the tunnel were deformed to a certain extent. Even if the support structure was destroyed, the vertical displacement of the tunnel floor was still low, indicating that the support structure effectively restrained the floor heave.

Through comparison of Figures 17(f) and 10(f), the model did not present overall sliding, and no " $X$ " type failure feature existed. Also, the supporting structure

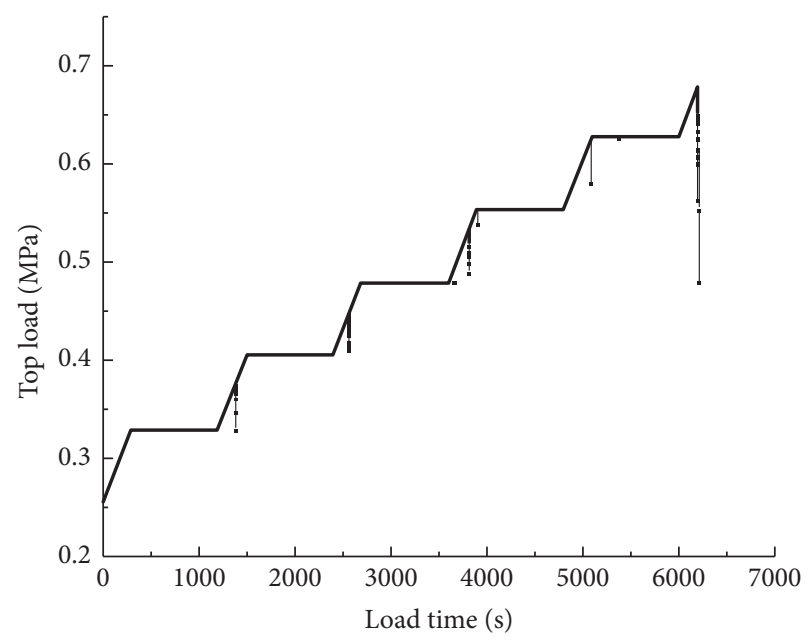

FIgURE 15: Variation of load of support model with testing time.

improved the stress situation of surrounding rock, while the surrounding rock and the supporting structure became a common carrier to avoid the phenomenon of displacement concentration caused by stress concentration. The supporting structure effectively improved the strength of the surrounding rock, slowing down the breaking of the surrounding rock, as well as maintaining the stability of the surrounding rock. Figure 17(f) reveals that the ultimate failure reason of the surrounding rock was the failure of the supporting structure caused by the collapse of the upper surrounding rock.

5.2. Horizontal Displacement. The cloud diagram of horizontal displacement distribution with support model under different loads is presented in Figure 18. It could be observed that no significant change in the horizontal displacement of the tunnel occurred at the early stage $(0.25 \mathrm{MPa}-0.32 \mathrm{MPa})$, when the wall rock and support acted together. In the middle stage of combined action of surrounding rock and support (0.48 MPa-0.58 MPa), horizontal displacement mainly occurred in the two sides of the tunnel. Prior to the support structure failure $(0.67 \mathrm{MPa})$, through comparison of Figures 18(f) and 11(f), the horizontal displacement of the two sides of the tunnel always maintained a small development, while the horizontal displacement of the arch roof significantly changed. This indicated that the support structure effectively limited the development of the horizontal displacement, leading to the force change of the whole model from shear horizontal tension to vertical compression. In summary, under different loads, the horizontal displacement of the tunnel did not present a large mutation or inflection point. The support structure effectively limited the development of the horizontal displacement. Also, the horizontal displacement around the tunnel always maintained a small fluctuation, consequently ensuring the stability and safety of the tunnel itself. The vertical displacement of the top of the model appeared "blocky," which indicated that the shallow surrounding rock was damaged. 


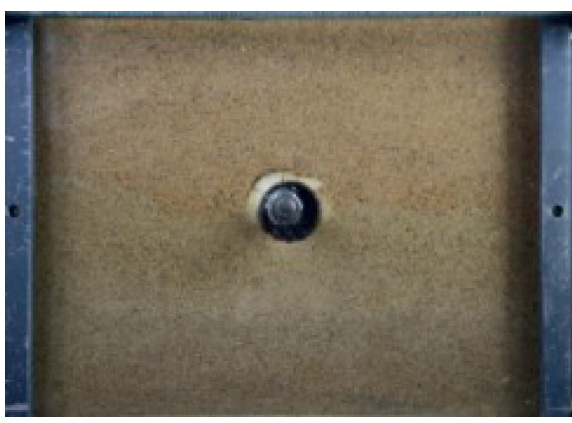

(a)

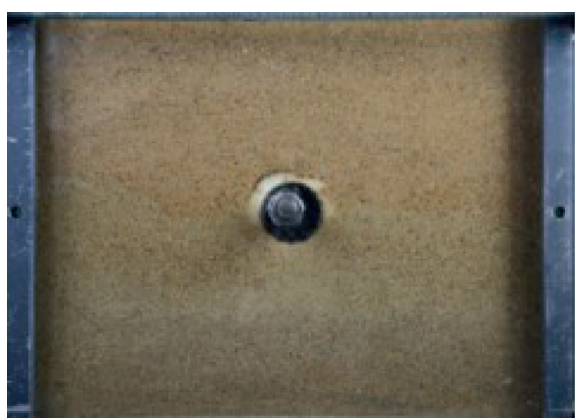

(c)

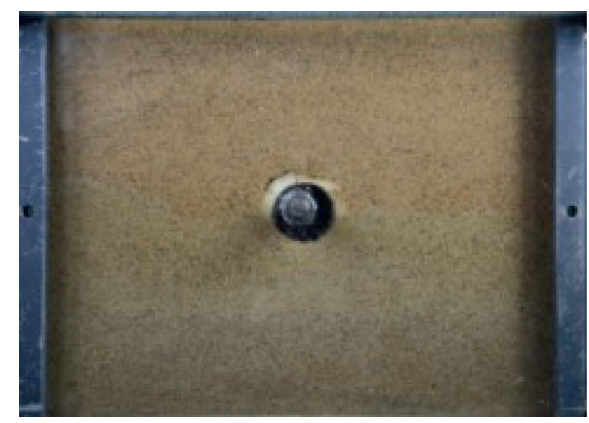

(b)

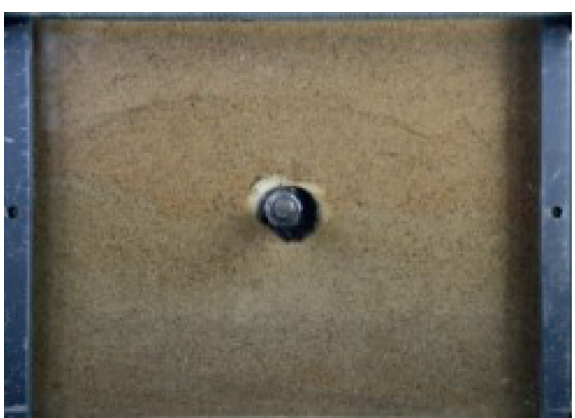

(d)

Figure 16: Main test image with support model. (a) $0.25 \mathrm{MPa}$. (b) $0.48 \mathrm{MPa}$. (c) $0.58 \mathrm{MPa}$. (d) $0.67 \mathrm{MPa}$.

5.3. Maximum Shear Strain. The maximum shear strain cloud diagram with support model under different loads is presented in Figure 19. It could be observed that the maximum shear strain of the rock mass had no apparent change in the early stage $(0.25 \mathrm{MPa}-0.32 \mathrm{MPa})$, when the surrounding rock and the support acted together. The maximum shear strain always appeared near the arched waist on both sides of the tunnel, while the shear strain of the rock mass at other positions was quite low. Through combination of surrounding rock and supporting medium $(0.48 \mathrm{MPa}$ to $0.63 \mathrm{MPa})$, the maximum shear strain of rock mass around the tunnel is at the two sidewalls and arch waist, demonstrating that the tunnel surrounding rock burst occurred mainly at the waist place, to the two wall arches. As the top load increased, the two sidewalls of rock burst gradually expanded to the vault, the tunnel top left, and upper right position with rapid enlargement of maximum shear strain of rock mass. Before the supporting structure damage $(0.67 \mathrm{MPa})$, tunnel surrounding rock mass of fracture was mainly concentrated in the tunnel vault and the two sidewall areas. In conclusion, timely support limited the deformation and fracture of surrounding rock and improved its bearing capacity.

5.4. Quantitative Analysis of Displacement Evolution of Surrounding Rock. Four measuring points were selected from the top, left wall, right wall, and bottom of the analyzed image tunnel for quantitative analysis of the total displacement of the measuring points, as presented in Figure 20. As the top load increased, the displacement of the top, the bottom, and the sidewalls of the surrounding rock basically did not change before the top load was $0.40 \mathrm{MPa}$, which indicated that the supporting structure effectively limited the development of the surrounding rock. After $0.40 \mathrm{MPa}$, the total displacement of surrounding rock of the top, bottom, and two walls presented an apparent differentiation and growth. As the load increased, the displacement of the top, left, and right walls tended to be consistent, while the displacement of the bottom wall remained basically unchanged. When the wall rock was finally destroyed $(0.67 \mathrm{MPa})$, the total displacement of the measuring points on the top of the wall rock was $25.54 \mathrm{~mm}, 25.02 \mathrm{~mm}$, $23.02 \mathrm{~mm}$, and $1 \mathrm{~mm}$.

5.5. Interaction between Surrounding Rock and Support during Loading. As it could be observed from Figures 21 and 22, the interaction between surrounding rock and support could be divided into three stages.

In the first stage, the surrounding rock and the support came into contact with each other and had a preliminary effect. In the beginning of the first stage (before $1500 \mathrm{~s}$ ), the surrounding rock gradually released pressure during deformation, which was manifested as the surrounding rock stress increased. Meanwhile, the supporting structure bore the deformation pressure of surrounding rock, which was manifested to be increased. In the middle and later periods of the first stage (1500s-3900s), top, bottom, and the two walls showed an apparent differentiation and growth of the surrounding rock stress value. Different from the the horizontal stress was higher than the vertical stress in the case of no support, curve steep type characteristics and laws was presented different performances for the top and bottom 


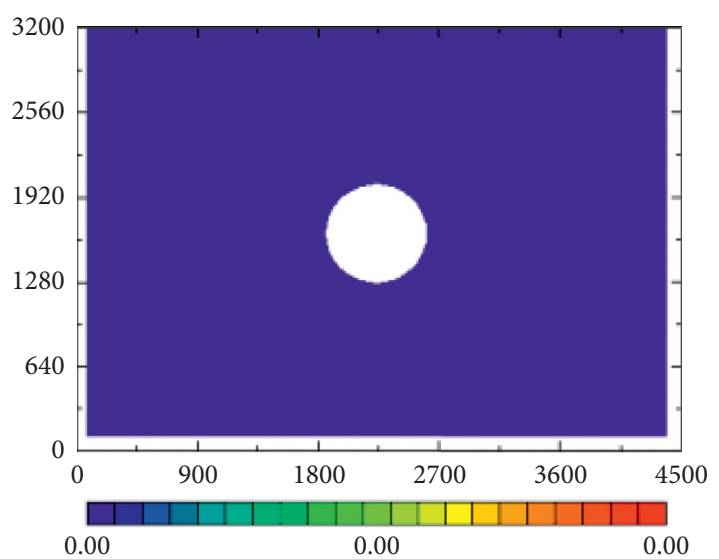

(a)

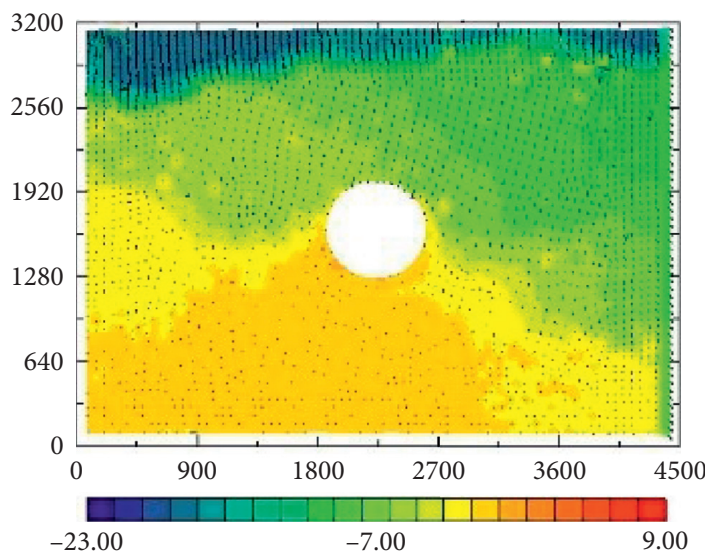

(c)

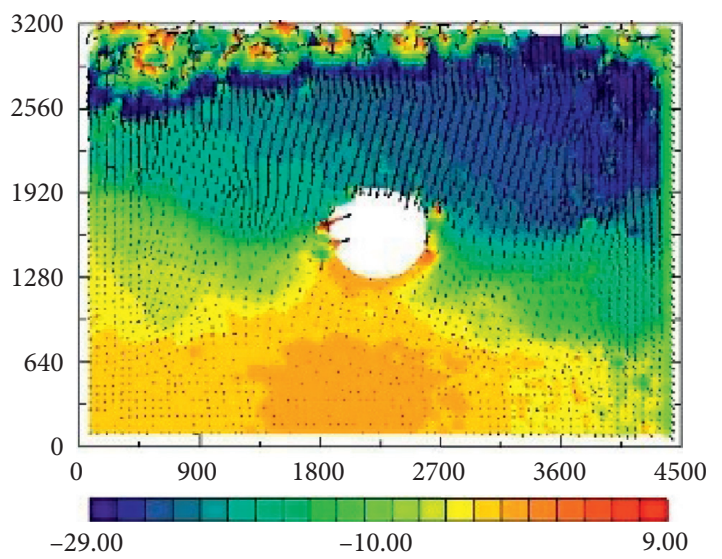

(e)

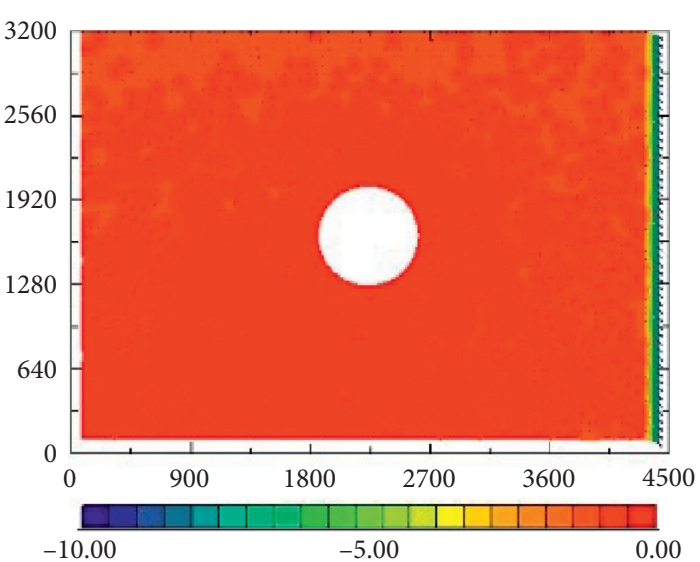

(b)

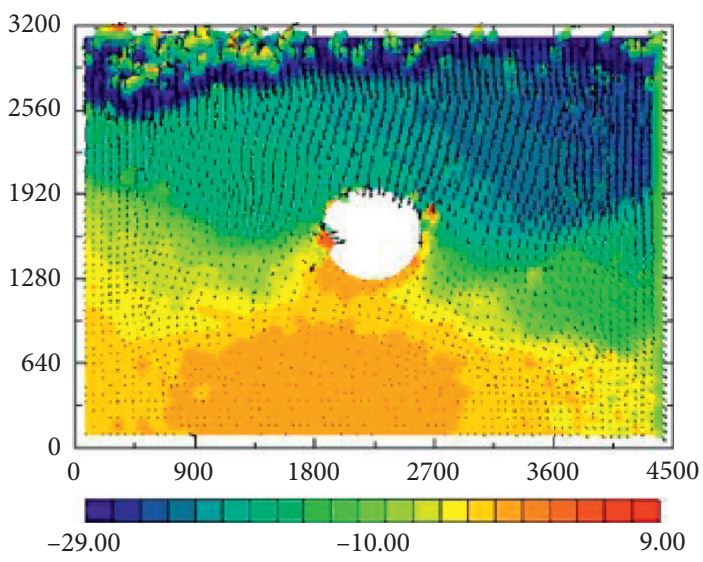

(d)

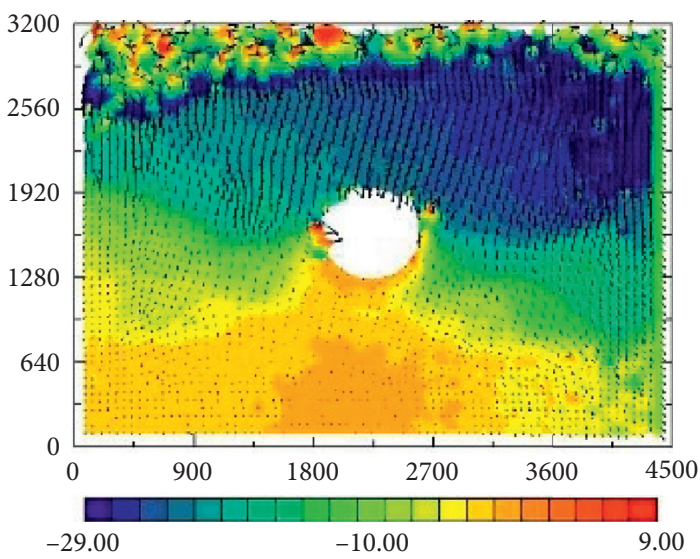

(f)

FIGURE 17: Vertical displacement cloud map with support mode. (a) $0.25 \mathrm{MPa}$. (b) $0.32 \mathrm{MPa}$. (c) $0.48 \mathrm{MPa}$. (d) $0.58 \mathrm{MPa}$. (e) $0.63 \mathrm{MPa}$. (f) $0.67 \mathrm{MPa}$.

vertical stress.. Also, two horizontal stresses of the sidewall were lower, and the maximum principal stress of the support structure was characterized by top and bottom of the horizontal stress sudden increase. Moreover, two vertical sidewall stresses increased slowly. This demonstrated that the supporting structure improved the stress state of the surrounding rock. The supporting structure could change the stress state of the surrounding rock surface from local tensile and shear stress to vertical compression, preventing the occurrence of internal tensile and shear stress in the surrounding rock, as well as reducing the stress concentration, while increasing the radial stress in the surrounding rock and reducing the tangential stress.

The second stage is the balance of interaction between surrounding rock and support (3900s-6050s). At the top load step growth, the surrounding rock and support 


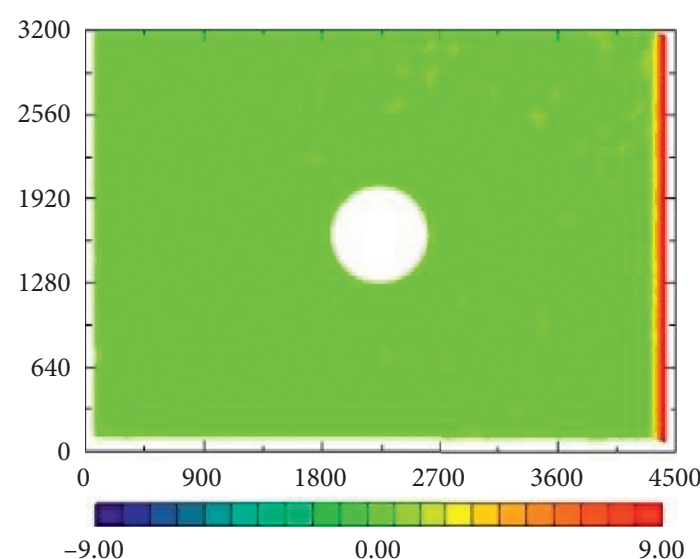

(a)

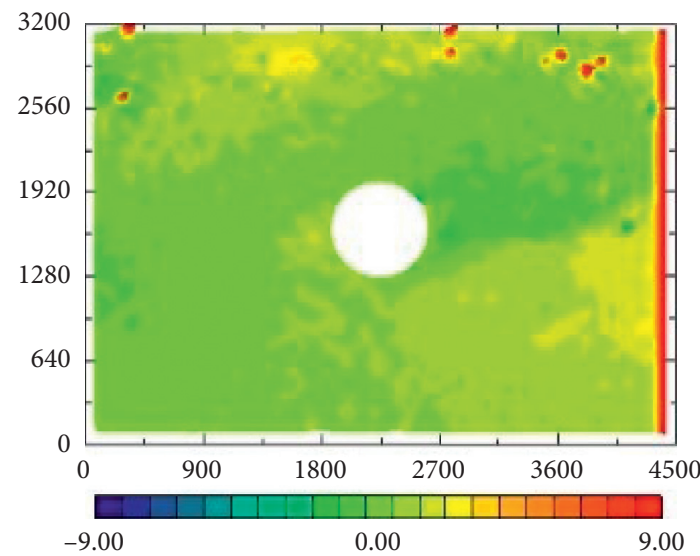

(c)

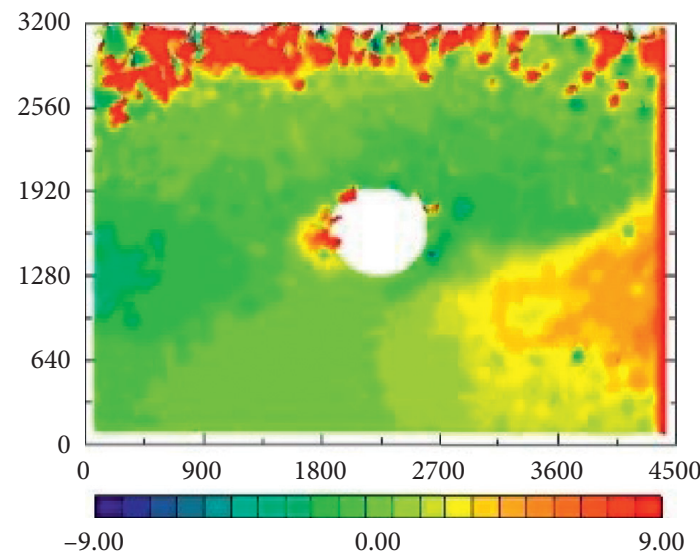

(e)

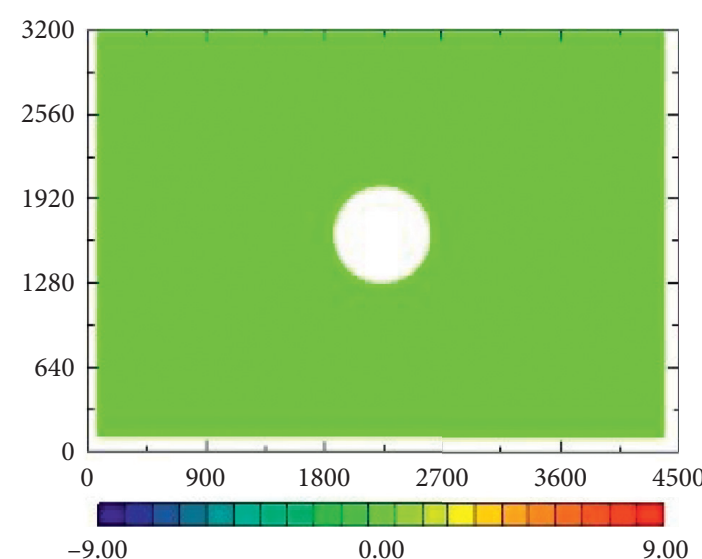

(b)

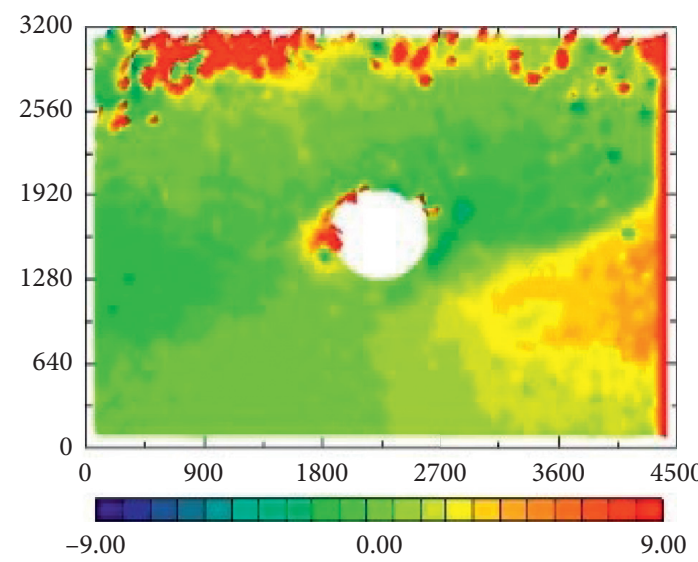

(d)

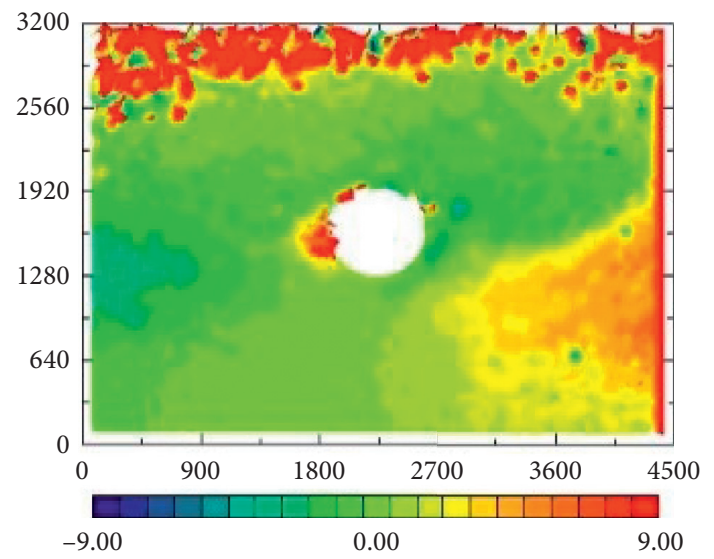

(f)

Figure 18: Horizontal displacement cloud map with support model. (a) 0.25 MPa. (b) $0.32 \mathrm{MPa}$. (c) $0.48 \mathrm{MPa}$. (d) $0.58 \mathrm{MPa}$. (e) $0.63 \mathrm{MPa}$. (f) $0.67 \mathrm{MPa}$.

sustained balance, at every stage of stress adjustment, while the performance for supporting structure continued to provide support resistance, leading to supporting structure stress increase. In addition, under the action of support resistance of surrounding rock, the trend of further deformation and destruction slowed down. Each part of stress continued to decay. The maximum principal stress of supporting structure gradually increased, but the level of the top and bottom stress changed far more than the vertical stress apparently for both sidewalls. To provide further evidence, the supporting structure of support resistance effectively suppressed the tunnel walls of two horizontal stresses, to avoid the shear slip of surrounding rock. The surrounding rock and supporting structure became the mechanical stable tunnel structure in each stage of interaction. 


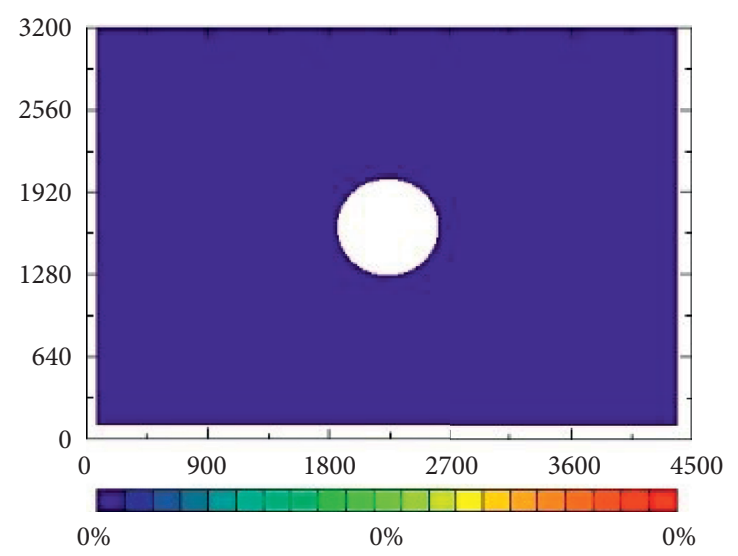

(a)

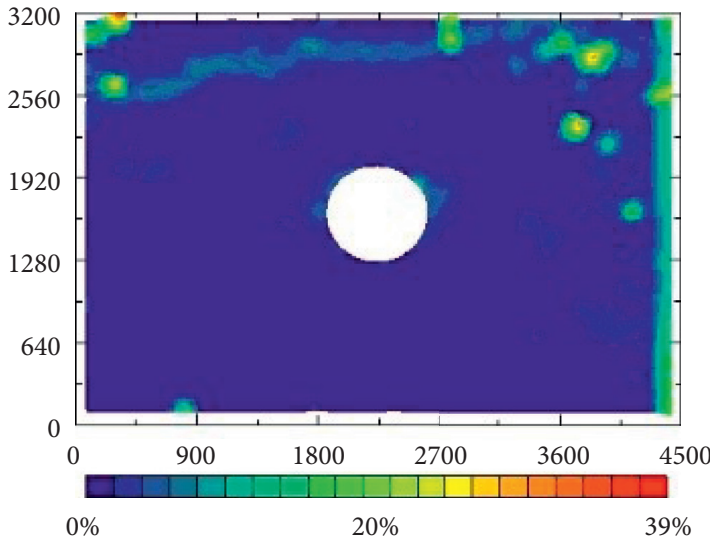

(c)

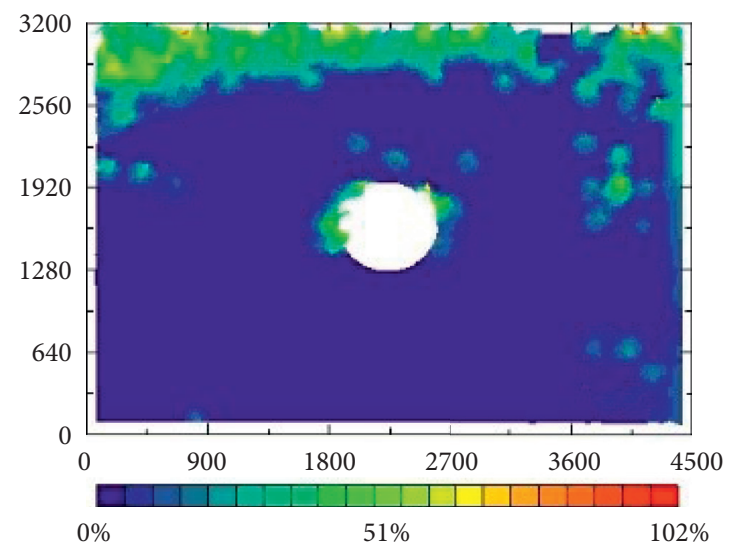

(e)

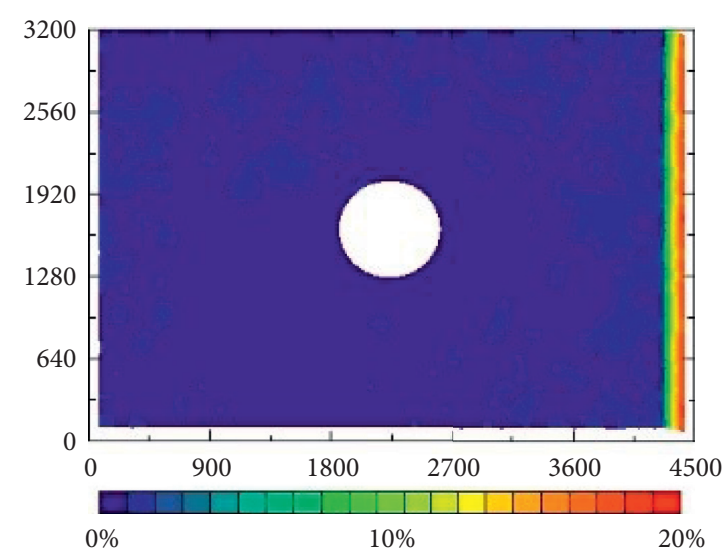

(b)

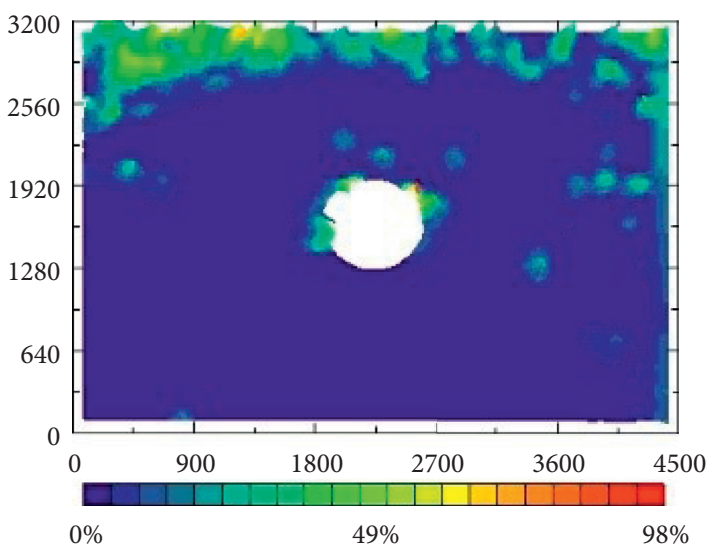

(d)

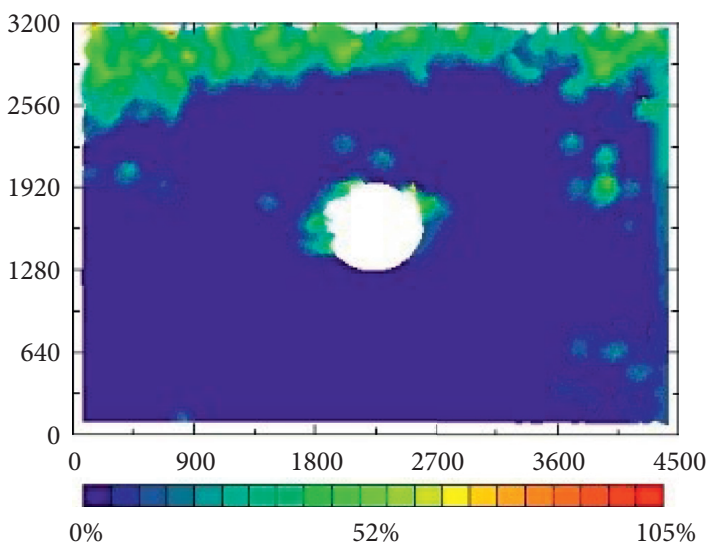

(f)

Figure 19: Maximum shear strain cloud image with support model. (a) $0.25 \mathrm{MPa}$. (b) $0.32 \mathrm{MPa}$. (c) $0.48 \mathrm{MPa}$. (d) $0.58 \mathrm{MPa}$. (e) $0.63 \mathrm{MPa}$. (f) $0.67 \mathrm{MPa}$.

The third stage, the "instability" state of surrounding rock and support (6050s-6200s), demonstrated that as the top load increased, the original equilibrium state broke, the supporting resistance reached the maximum value, the supporting structure was damaged, and the surrounding rock was unstable as a whole.

In summary, the surrounding rock presented the characteristics of failure, stability, and refailure under the top load increase. The supporting resistance improved the internal stress environment of the surrounding rock, to ensure the surrounding rock stability of the tunnel.

\section{Comparison of Deformation and Fracture Results of Surrounding Rock}

Combined with the maximum shear strain cloud diagram of surrounding rock and the vertical displacement cloud diagram, the model sketch with and without support was drawn, when 


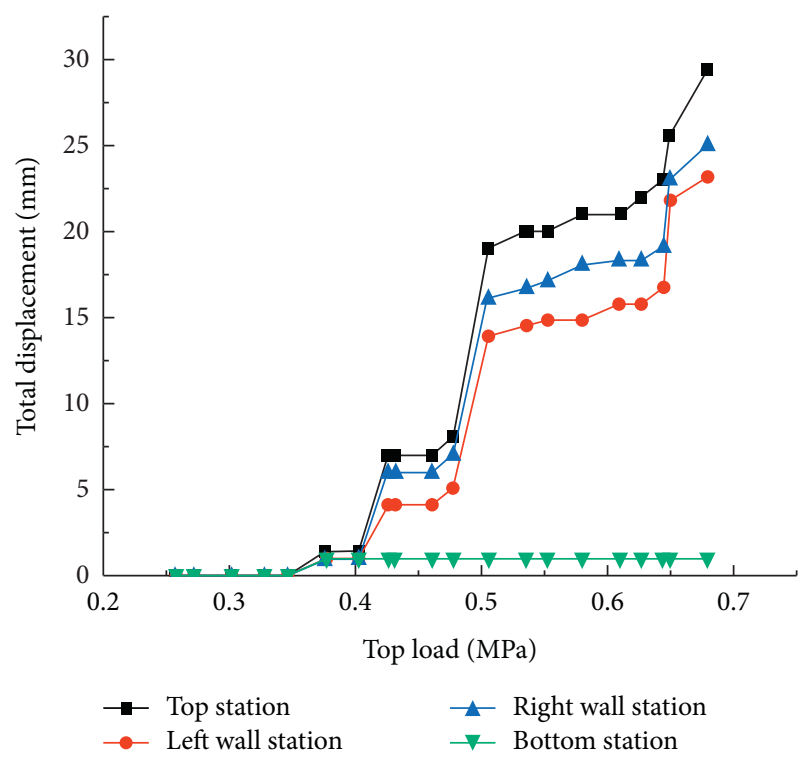

FIGURE 20: Load-displacement curve at top of supported model.

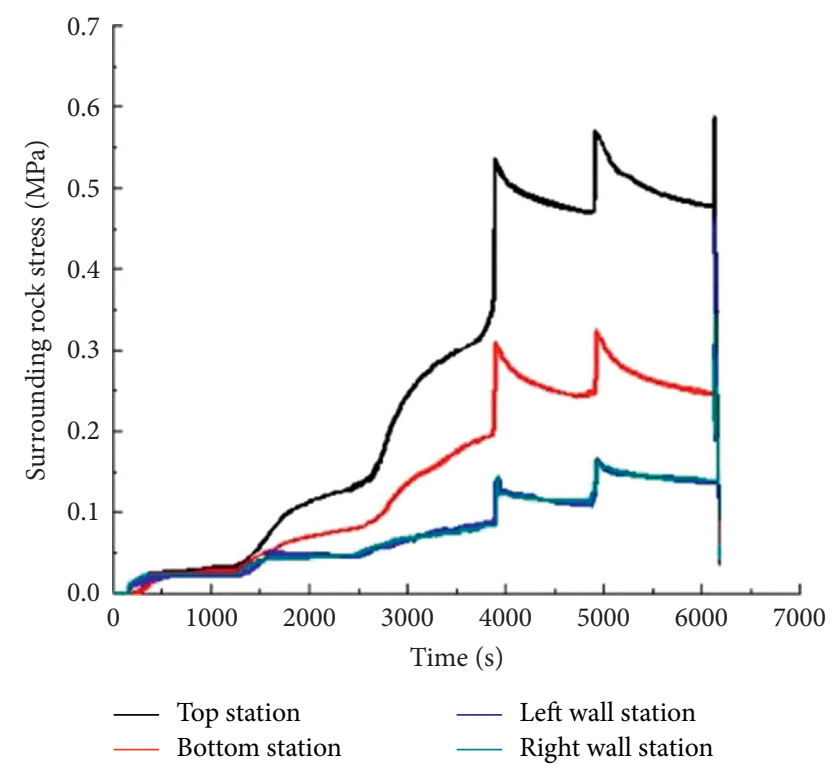

FIGURE 21: Surrounding rock stress variation curve with time.

the top load was $0.55 \mathrm{MPa}$ and the maximum shear strain was 25\%, as presented in Figures 23(a) and 23(b). When the top load was $0.67 \mathrm{MPa}$ and the maximum shear strain was $50 \%$, the corresponding model sketch is presented in Figure 23(c). Through the deformation range and deformation mode analysis, the fracture results of the composite stratum with or without support were compared and explained.

6.1. Deformation Range. When the top load was $0.55 \mathrm{MPa}$, the deformation range of the left wall of the unsupported model was approximately $20 \mathrm{~mm}$ long and $28 \mathrm{~mm}$ high. The deformation range of the right wall was approximately $25 \mathrm{~mm}$ long and $38 \mathrm{~mm}$ high Figure 23(a). The deformation around the tunnel with support model was low, while the

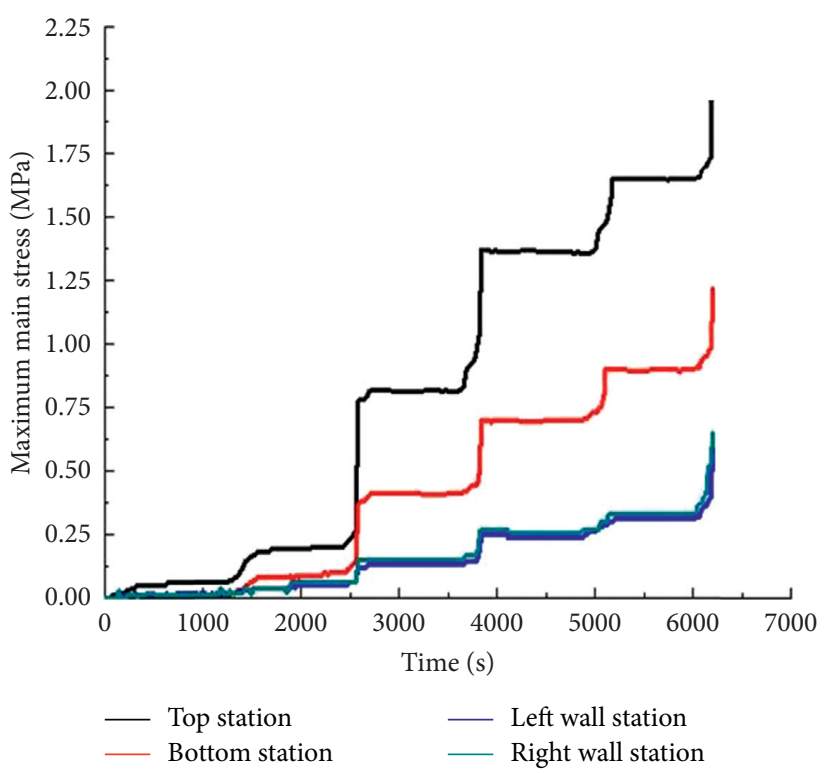

FIgURE 22: Maximum principal stress curve of supporting structure.

deformation range was a semicircle of $10 \mathrm{~mm}$ in radius Figure 23(b). When the top load was $0.67 \mathrm{MPa}$, a support model existed, Figure 23(c). The deformation range of the right wall was approximately $20.5 \mathrm{~mm}$ long and $23.5 \mathrm{~mm}$ high.

6.2. Deformation Mode. Compared to the support models of Figures 23(a) and 23(b), the model had no overall sliding and no " $X$ " failure feature. Ultimate damage of surrounding rock of the model was as follows: at the top of the vertical stress, where the surrounding rock had shallow high residual strength after loading damage, the effects of the hulking high swelling capacity (capacity expansion) caused the sinking to be fast as well as the instability of surrounding rock, also producing the phenomenon of abscission layer (layer deformation), along with horizontal cracks, Figure 23(c). The overall collapse failure of the surrounding rock at the top connection of the tunnel would eventually lead to the failure of the protection of the pipe piece and to the instability failure of the tunnel. Combined with time-load curve analysis, the embedded pipe segment model could increase the bearing capacity of surrounding rock by approximately $20 \%$.

\section{Analysis of Support Resistance of Multiple Retaining Structures under Static Conditions in Unbiased Tunnels}

Surrounding rock pressure $P_{a}$ was equal to and opposite to support resistance $P_{s}$. The resistance of supporting structure to surrounding rock was related to the stiffness of supporting structure. The higher the stiffness of the supporting structure was, the higher the ability to prevent surrounding rock from deformation was. The radial stiffness $K_{S}$ of circular concrete lining and the supporting force $P_{s}$ provided by it could be obtained from the hollow cylinder theory under external 


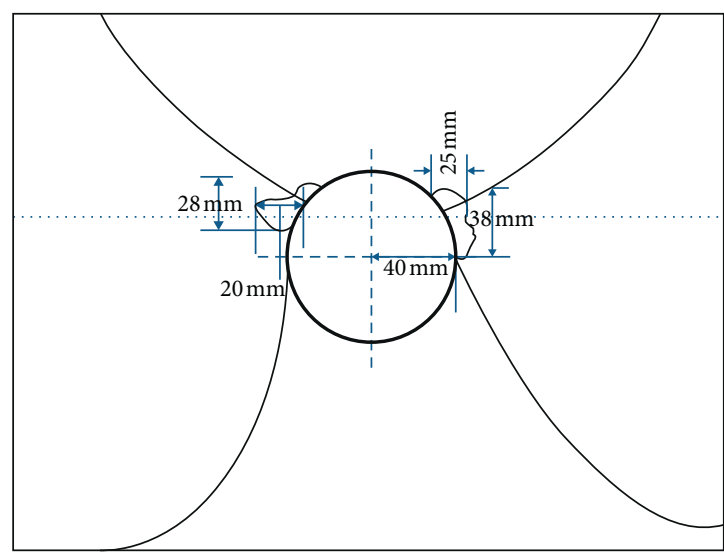

(a)

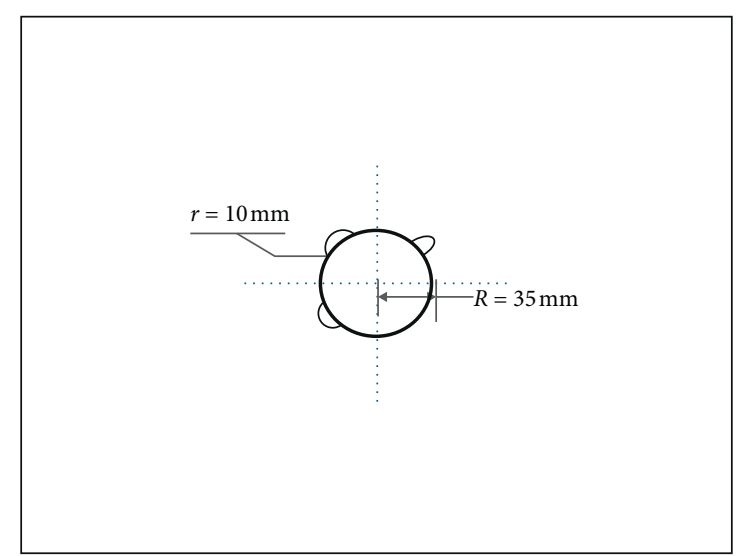

(b)

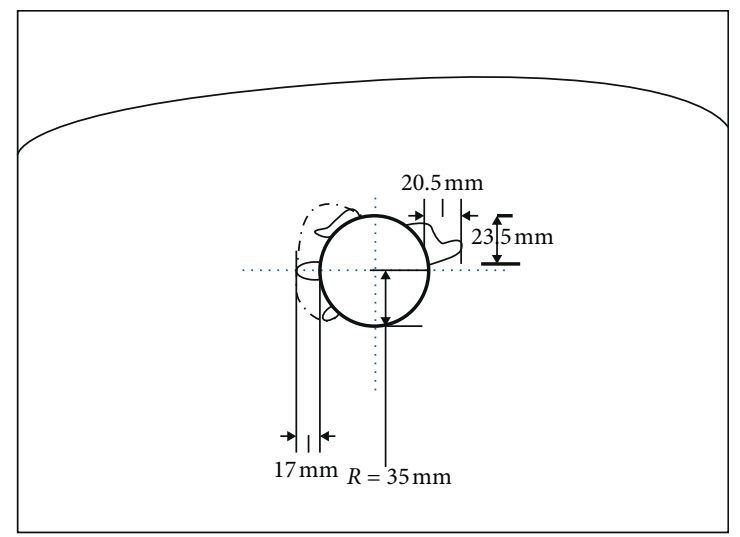

(c)

FIGURE 23: TBM tunnel surrounding rock deformation sketch of mixed strata with and without support. (a) Without support. (b) Support 1. (c) Support 2.

radial pressure as stated by Gesta et al. [16]. The supporting resistance calculation of the supporting structure is presented in Figure 24.

Radial stiffness of concrete segments $K_{S}^{1}$ is

$$
K_{S}^{1}=\frac{r^{2}-\left[r-\left(t_{s 1}+t_{s 2}\right)\right]^{2}}{r\left(1+v_{s 1}\right)\left[\left(1-2 v_{s 1}\right) r^{2}+\left[r-\left(t_{s 1}+t_{s 2}\right)\right]\right]^{2}} E_{S 1} \text {. }
$$

Radial stiffness of bean gravel pack $K_{S}^{2}$ is

$$
K_{S}^{2}=\frac{r^{2}-\left(r-t_{s 1}\right)^{2}}{r\left(1+v_{s 2}\right)\left[\left(1-2 v_{s 2}\right) r^{2}+\left(r-t_{s 1}\right)^{2}\right]} E_{S 2} .
$$

Support resistance of concrete pipe segment $P_{s 1}$ is

$$
P_{s 1}=\frac{\sigma_{\mathrm{CS} 1}}{2}\left[1-\left(\frac{r-\left(t_{s 1}+t_{s 2}\right)}{r}\right)^{2}\right] \text {. }
$$

Support resistance of pea gravel pack $P_{s 2}$ is

$$
P_{s 2}=\frac{\sigma_{\mathrm{CS} 1}}{2}\left[1-\left(\frac{r-\left(r-t_{s 1}\right)}{r}\right)^{2}\right] \text {, }
$$

where $v_{s 1}$ is the Poisson's ratio of concrete segments, $v_{s 2}$ is the Bean gravel pack Poisson ratio, $\sigma_{\mathrm{CS} 1}$ is the compressive strength of concrete segments, $\sigma_{\mathrm{CS} 2}$ is the compressive

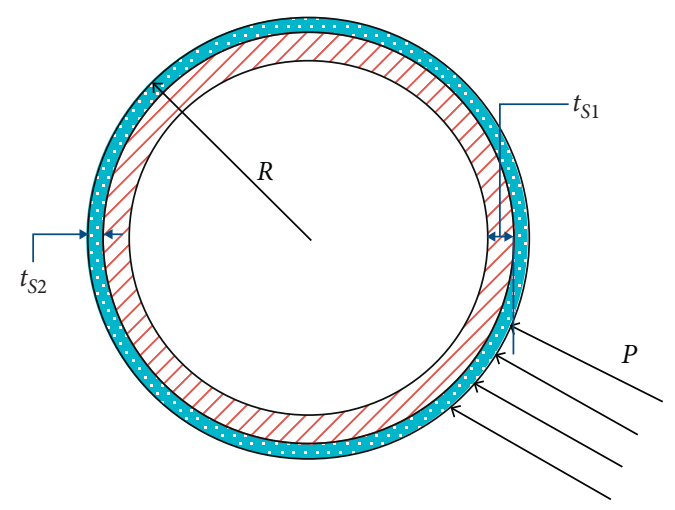

Figure 24: Calculation diagram of supporting structure of supporting force (unbiased tunnels).

strength of the bean gravel pack, $t_{s 1}$ is the thickness of concrete segments, $t_{s 2}$ is the thickness of the bean gravel pack, $E_{S 1}$ is the elastic modulus of concrete pipe segment, and $E_{S 2}$ is the elastic modulus of bean gravel pack.

During excavation and support of TBM tunnel, the combined support of concrete pipe slice and bean gravel backfilling grouting was adopted. When the support was 
erected on the same section at the same time, the stiffness of the joint support was equal to the sum of the stiffness of each independent support system, as follows:

$$
K_{S}^{\mathrm{com}}=\sum_{i}^{n} K_{S}^{i}
$$

where $K_{S}^{\text {com }}$ is the stiffness of combined support and $K_{S}^{i}$ is the stiffness of type I independent support.

At this time frame, the maximum support pressure value of the entire support is

$$
P_{S}^{\max , \text { com }}=K_{S}^{\text {com }} \cdot \min \left(\frac{P_{S}^{\max , 1}}{K_{S}^{1}}, \frac{P_{S}^{\max , 2}}{K_{S}^{2}}\right),
$$

where $P_{S}^{\max , c o m}$ is the maximum support pressure for combined support, $P_{S}^{\max , 1} / K_{S}^{1}$ is the maximum support pressure for concrete pipe segment support, and $P_{S}^{\max , 2} / K_{S}^{2}$ is the maximum support pressure for gravel pack support.

\section{Conclusions}

For the various problems of excavation, tube simulation, deformation, and force measurement in the small-scale model test of deep composite stratum TBM tunnel, tunnelboring machine simulation experimental device, model segment ring prefabrication device, digital photography, and measurement technology were comprehensively adopted. This was supplemented by theoretical derivation, through research and analysis of the deformation and rupture characteristics of surrounding rock with and without support, revealing the space-time effect of deformation and rupture of surrounding rock under the support. The research results were as follows:

(1) When no support existed and when the burial depth or dynamic stress concentration coefficient reached a certain value, the "combination effect" of "soft and hard unevenness" of the composite formation led the space-time effect of tunnel surrounding rock deformation to be concentrated in the development of time and the deformation of the surrounding rock starting from the sides of the arch waist at the junction of the composite stratum, along with four arcs being derived to cause shear sliding, resulting in overall collapse and destruction.

(2) After the support was applied, the time effect of the surrounding rock deformation was concentrated on the three stages of interaction between the surrounding rock and the support. The space-time effect of the surrounding rock deformation was concentrated on the surrounding rock and the support. The three stages of the action were the initial contact, the equilibrium, and the "stability" states. The spatial effect was concentrated on the following: the most severe area of deformation and destruction of surrounding rock was shallow surrounding rock, and the sub-violent area was the corner of the sidewall. When the top load continuously increased, the surrounding rock was characterized by failure-stability-redestruction. The support resistance improved the stress environment inside the surrounding rock, and the stress state of the surrounding rock changed from local tension to vertical compression. This ensured the stability of the surrounding rock of the tunnel. As the vertical stress increased, the shallow surrounding rock exceeded its limit and the strength decreased. The shallow residual rock had higher residual strength after loading failure, and the higher expansion resulted in the expansion and depth increase. Under the loose rupture of the surrounding rock, the deformation of the surrounding rock sharply increased, resulting in the failure of the support and the ultimate instability of the tunnel.

(3) Based on the hollow cylinder theory, the calculation method of support resistance of TBM tunnel multisupport structure under static conditions was derived.

\section{Data Availability}

The data used to support the findings of this study are included in the article.

\section{Conflicts of Interest}

The authors declare no conflicts of interest.

\section{Authors' Contributions}

X. S. supervised the work; C. R. contributed to conceptualization; J. Y. wrote, reviewed, and edited the manuscript; J. D. was responsible for software; J. L. helped with visualization; B. G. conducted investigation. All authors read and approved the published version of the manuscript.

\section{Acknowledgments}

This research was funded by the National Science Foundation of China (Grant no. 51874311) and the National Basic Research Program of China (973 Program (Grant no. 2014CB046905).

\section{References}

[1] M. Lei, L. Peng, and C. Shi, "Model test to investigate the failure mechanisms and lining stress characteristics of shallow buried tunnels under unsymmetrical loading," Tunnelling and Underground Space Technology, vol. 46, pp. 64-75, 2015.

[2] X. G. Jin, B. W. Cui, and M. J. Wu, "Simulating and testing study on construction temporal-spatial effect of six lanes multi-arch tunnel," Advanced Materials Research, vol. 446-449, pp. 2149-2155, 2012.

[3] M. Wang, J. Li, L. Ma, and H. Huang, "Study on the characteristic energy factor of the deep rock mass under weak disturbance," Rock Mechanics and Rock Engineering, vol. 49, no. 8, pp. 3165-3173, 2016.

[4] Z. Zhang, S. Wang, and X. Huang, "Analysis on the evolution of rock block behavior during TBM tunneling considering the TBM-block interaction," Rock Mechanics and Rock Engineering, vol. 51, no. 7, pp. 2237-2263, 2018. 
[5] M. R. Zareifard and A. Fahimifar, "Analytical solutions for the stresses and deformations of deep tunnels in an elastic-brittleplastic rock mass considering the damaged zone," Tunnelling and Underground Space Technology, vol. 58, pp. 186-196, 2016.

[6] Z. Chu, Z. Wu, B. Liu, and Q. Liu, "Coupled analytical solutions for deep-buried circular lined tunnels considering tunnel face advancement and soft rock rheology effects," Tunnelling and Underground Space Technology, vol. 94, Article ID 103111, 2019.

[7] S. X. Lei, B. Gao, and Q. H. Xiao, "Analysis on the characteristics of displacement field distribution around the deep buried and great complex section tunnel," Advanced Materials Research, vol. 446-449, pp. 2251-2255, 2012.

[8] S.-Q. Yang, Y. Tao, P. Xu, and M. Chen, "Large-scale model experiment and numerical simulation on convergence deformation of tunnel excavating in composite strata," Tunnelling and Underground Space Technology, vol. 94, Article ID 103133, 2019.

[9] K. F. Chen, "Research and application of surrounding rock rupture evolution process and its control mechanism in deep tunne" Ph.D. thesis, China University of Mining and Technology, Xuzhou, China, 2009.

[10] Y. Bai and Z. C. Ding, Tunnel Boring Machine Construction Technology, China Building Industry Press, Beijing, China, 2008.

[11] Y. H. Li, C. Ren, Z. B. Lin, S. J. Zhang, and C. L. Gui, “Tunnel boring machine simulation experiment device," ChinesePatent; $201320325402,2013$.

[12] Y. Wen, S. X. Li, and Y. T. Fan, Construction Technology of Datong Rock Tunnel Full Face Tunnelling Machine, China Water \& Power Press, Beijing, China, 2013.

[13] M. F. Lei, L. M. Peng, C. H. Shi, and S. Y. Wang, "Experimental study on stress characteristics and failure mechanism of lining under shallow buried pressure tunnel," Journal of Central South University, vol. 44, pp. 3316-3325, 2013.

[14] L. C. Wang, "Limit analysis method for optimization of surrounding rock pressure and excavation footage of shallow buried pressure tunnel" Ph.D. thesis, Central South University, Changsha, China, 2011.

[15] Y. H. Li, Digital Photographic Measurement Technology and Its Application in Geotechnical Engineering Experiments, China University of Mining and Technology Press, Xuzhou, China, 2009.

[16] P. Gesta, J. Kerisel, and P. Londe, "Tunnel stability convergence-confinement method," Underground Space, vol. 4, pp. 225-232, 1980. 